\title{
Review Article \\ Surface Modification Chemistries of Materials Used in Diagnostic Platforms with Biomolecules
}

\author{
Mukesh Digambar Sonawane and Satish Balasaheb Nimse \\ Institute for Applied Chemistry and Department of Chemistry, Hallym University, Chuncheon 200-702, Republic of Korea \\ Correspondence should be addressed to Satish Balasaheb Nimse; satish_nimse@hallym.ac.kr
}

Received 10 February 2016; Revised 8 April 2016; Accepted 10 April 2016

Academic Editor: Dimosthenis L. Giokas

Copyright ( 2016 M. D. Sonawane and S. B. Nimse. This is an open access article distributed under the Creative Commons Attribution License, which permits unrestricted use, distribution, and reproduction in any medium, provided the original work is properly cited.

\begin{abstract}
Biomolecules including DNA, protein, and enzymes are of prime importance in biomedical field. There are several reports on the technologies for the detection of these biomolecules on various diagnostic platforms. It is important to note that the performance of the biosensor is highly dependent on the substrate material used and its meticulous modification for particular applications. Therefore, it is critical to understand the principles of a biosensor to identify the correct substrate material and its surface modification chemistry. The imperative surface modification for the attachment of biomolecules without losing their bioactivity is a key to sensitive detection. Therefore, finding of a modification method which gives minimum damage to the surface as well as biomolecule is highly inevitable. Different surface modification technologies are invented according to the type of a substrate used. Surface modification techniques of the materials used as platforms in the fabrication of biosensors are reviewed in this paper.
\end{abstract}

\section{Introduction}

In recent years, biosensors became one of the indispensable tools as point-of-care (PoC) diagnostics [1]. A biosensor is an analytical device which combines a biological component with a physicochemical detector, used for the detection of an analyte [2]. The general aim of the design of any biosensor is to allow the rapid, accurate, and convenient testing in the PoC settings where the patient is receiving care [3].

Advances in biosensor technologies have enabled developing the diagnostic biosensors which have high accuracy, high speed, and an ability of parallel screening of multiple analytes [4]. So far, numerous types of biosensors have been developed [5]. Classification of the biosensors can be rationalized by looking at the principle biomolecular interactions used in that particular biosensor. In general, most of the biosensors are majorly based on the antibody/antigen interactions [6], enzymatic interactions [7], DNA-DNA interactions [1, 8], cellular structures/cells [9], or biomimetic materials [10, 11].

Irrespective of a type of biosensor and a final detection step of an analyte either at the solid-liquid interface or in the solution phase involving nanoparticle (NP), the surface attachment of antibody, enzyme, DNA, or cell is inevitable. It is well known that the conformation of biomolecules such as antibodies and enzymes plays a crucial role in determining both efficiency and selectivity of these molecules for analytes [12]. Therefore, the performance of the biosensors greatly depends on the surface chemistry of the materials used and also the chemistries used in the conjugation of the components of biosensors such as antibodies and enzymes on the surface. The attachment chemistries used for the immobilization processes can alter the natural molecular environment of proteins, thus resulting in the loss of their activity indicated by a significant drop in the sensitivity and selectivity. Various surfaces used for the immobilization of biomolecules include silicon, glass (silicon dioxide), nitrocellulose, gold, silver, polystyrene, and graphene. In this critical review, we have highlighted the materials and respective chemistries used for the immobilization of biomolecules. Merits and demerits of some of the materials and their surface modification chemistries for the application in the selective and sensitive detection of analytes are discussed. 


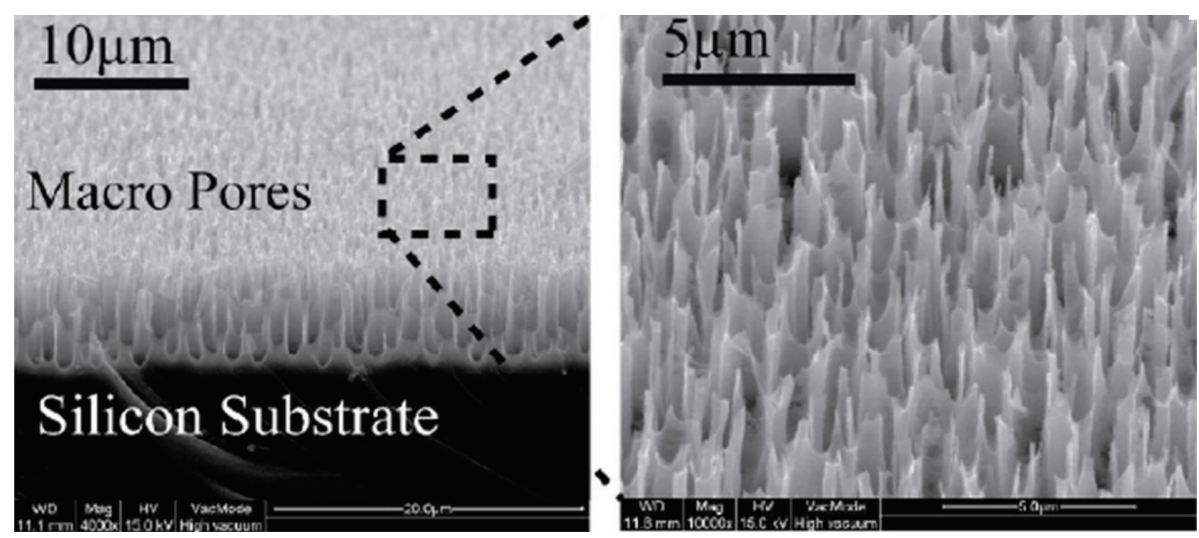

FIGURE 1: The macroporous surface of modified silicon (adapted from [13]).

\section{Material and Techniques for Surface Modification}

Modification of a surface is crucial to producing biomolecule detection platforms. In general, the functional groups present in biomolecules are allowed to react with the functional groups on the modified surfaces for their immobilization. Most common biomolecules immobilized on the surface for the fabrication of the diagnostic devices are DNA, proteins, and carbohydrates. DNA oligomers can be synthesized to have terminal amine and aldehyde groups. Proteins naturally contain amine, sulfhydryl, and carboxylic acid functional groups. Carbohydrates, in general, have hydroxyl functional groups and amine functional groups in case of glucosamine. Depending on these groups, surfaces of the substrate are modified for biomolecule attachment. The efficiency of the detection platform is strongly affected by the proper immobilization of biomolecules. Therefore, the materials and their surface modification chemistries are discussed in detail. The common surfaces used in the diagnostic devices are silicon, glass slide, glass membranes, carbon, nitrocellulose, polystyrene, silver, gold, and so forth.

2.1. Silicon. Silicon is the element of periodic table that rarely occurs in pure form. It occurs in a stable oxidized form. The typical application of silicon in electronic devices is as a semiconductor. Electrochemical detection of protein is well known because it is label-free and allows real-time detection. Physical adsorption is one of the choices for antibody immobilization as it does not need temperature and humidity controls [13]. The shorter time of immobilization makes assay faster compare to other methods [14]. Porous form of silicon surface makes it more efficient for the immobilization due to formation of pseudo-three-dimensional surface $[15,16]$. The porous silicon (P-Si) surface shows high spot homogeneity, low internal fluorescence, little wetting ability, and less nonspecificity [17]. Depending on the pore size the P-Si has three categories, microporous (less than $10 \mathrm{~nm}$ ), mesoporous $(10-50 \mathrm{~nm})$, and macroporous (larger than $50 \mathrm{~nm})$. It has been reported that the macroporous silicon surface is highly suitable for antibody immobilization [13]. There are several reports on the techniques used for the fabrication of silicon surface.

2.1.1. Electrochemical Modification. The physisorption of biomolecules on the P-Si depends heavily on its micro- and nanomorphology controlled by the surface etching conditions and selection of silicon type. A great deal of work is reported on the fabrication of micro- and nanoporous silicon for antibody adsorption $[18,19]$. Lee et al. selected a boron silicon wafer with a specific resistivity $(\sim 6-8 \Omega \mathrm{cm})$ and placed it in the electrochemical cell.

As depicted in Figure 1, a self-supporting layer of P$\mathrm{Si}$ is fabricated by growing an anodic oxide followed by its dissolution using an electropolishing current in a $15 \%$ hydrofluoric acid solution leading to the formation of pores. The macroporous P-Si is then cut into pieces and fitted in microtitre plate for deposition of capture antibodies (cAb) for sandwich immunoassay [20]. There are several reports on the applications of the P-Si surfaces for the electrochemical detection of various chemicals and bacteria $[21,22]$.

2.1.2. Covalent Modification. P-Si microparticles have high and unique reflectance properties. The antibodies which can target and capture specific antigens or cells can be covalently immobilized on the P-Si microparticles. The hydrideterminated surface of the P-Si microparticles can be passivated by hydrosilylation with dialkyne species. Guan and coworker used $\mathrm{Cu}(\mathrm{I})$-catalyzed alkyne-azide cycloaddition (CuAAC) followed by succinimidyl activation reaction for coupling of the antibodies to P-Si. As shown in Figure 2, antibody modified P-Si microparticles were employed for the selective capture and detection of HeLa cells [23]. Similar CuAAC based surface modification for adhesion of cell surface has also been reported [24].

Other applications of P-Si surface include fabrication of protein microarray for PSA detection with the limit of detection (LOD) of $800 \mathrm{fg} / \mathrm{mL}$. A successful covalent modification of P-Si has been reported by Rossi et al. for detection of MS2 virus with the LOD of $2 \times 10^{7}$ plaque-forming 


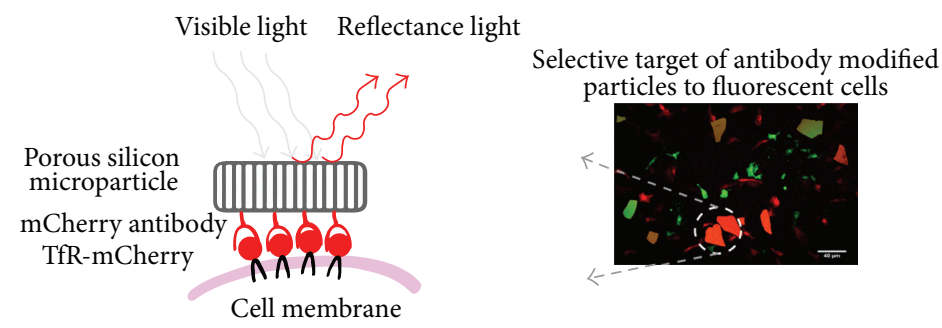

FIgURE 2: Covalent bonding of antibodies to P-Si microparticles for detection of cells (adapted from [23]).

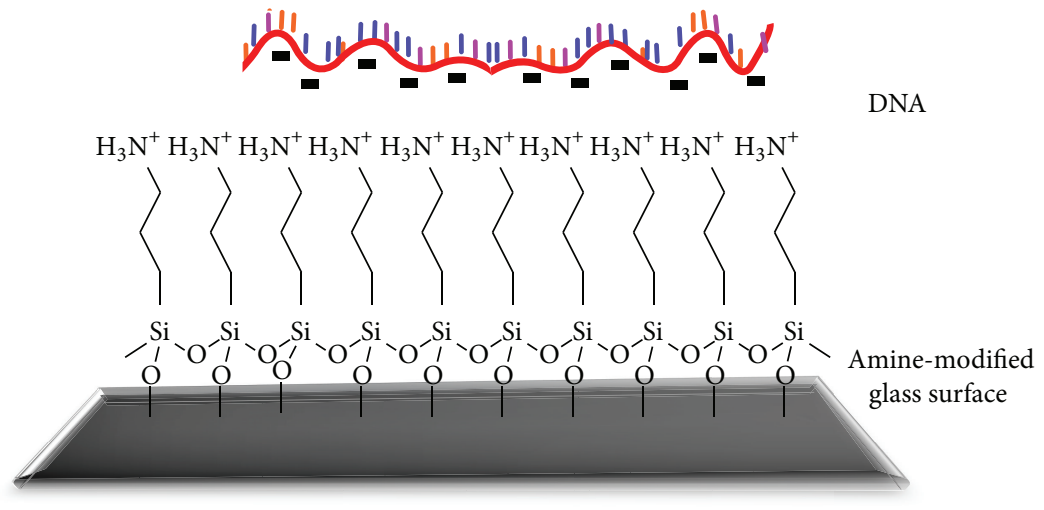

FIgURE 3: Physisorption of DNA on the amine-modified glass surface.

units per $\mathrm{mL}(\mathrm{pfu} / \mathrm{mL})$ [25]. As explained earlier, the strict fabrication protocol is needed for accurate size of pores. Change in the concentrations of reagents and change in current and time affect the reproducibility of the result. Other covalent ethylene glycol modified silicon surfaces for specific adsorption of protein through photochemical reaction [26] and silicon covalent surface modification for agarose crosslinking in form of catheter have been reported for infection inhibition and omental wrapping [27].

2.2. Glass $\left(\mathrm{SiO}_{2}\right)$. A glass is made up of a silicon dioxide $\left(\mathrm{SiO}_{2}\right)$. The oxide layer protects the silicon from chemical degradation and reactions. Silicon dioxide is abundant in nature and thermally stable due to a large number of silicon and oxygen bonds. Glass substrates are easily available and simple to handle and have high mechanical stability. Glass surfaces are widely used for the immobilization of DNA, proteins, and other low molecular weight biomolecules [28]. In diagnostic field, glass surface plays a crucial role as microarray platform for detection of various pathogenic DNA as well as biomarker protein $[29,30]$.

2.2.1. Physisorption Based Modification. Physical adsorption or physisorption is one of the simplest techniques used for the biomolecule immobilization on glass surfaces. As shown in Figure 3, the negatively charged phosphate backbone on DNA forms an ionic interaction with the positively charged surface of amine-modified glass surface through charge interactions [38].

Lemeshko et al. reported that the aminosilanization of the glass surface by treatment with 3-(aminopropyl) trimethoxysilane (APTMS) affords the positively charged surface. Unfortunately, the immobilization of DNAs with this method does not result in the reproducible DNA detection platform. Because the multiple interaction of negatively charged DNA backbone with the cationic surface orients it parallel to the glass surface, thus its availability for hybridization with the complimentary DNA (cDNA) is significantly low.

The random orientation of the immobilized DNAs is also related to the nonspecific hybridization and low reproducibility. The change in $\mathrm{pH}$ of solution and temperature significantly affects the performance of the platform based on the method of physisorption.

2.2.2. Covalent Modification. Due to various disadvantages of physisorption methods, the covalent surface modification strategy has been widely used. Covalent bond is stronger and more stable than electrostatic interaction at solution-surface interfaces [40, 41]. The glass surfaces and be modified with the different functional groups suitable for making covalent bonds with the biomolecules to be immobilized. In general, the biomolecules have amine, carboxylic acid, and sulfhydryl functional groups. These functional groups can be used for the immobilization of biomolecules on the surface. There are 


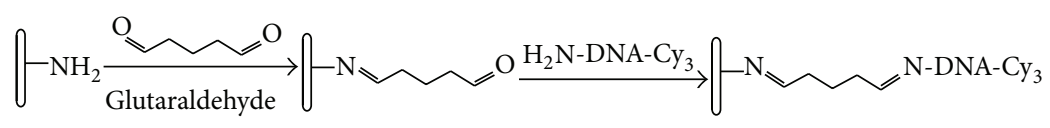

Scheme 1: Aldehyde modification of glass slide.

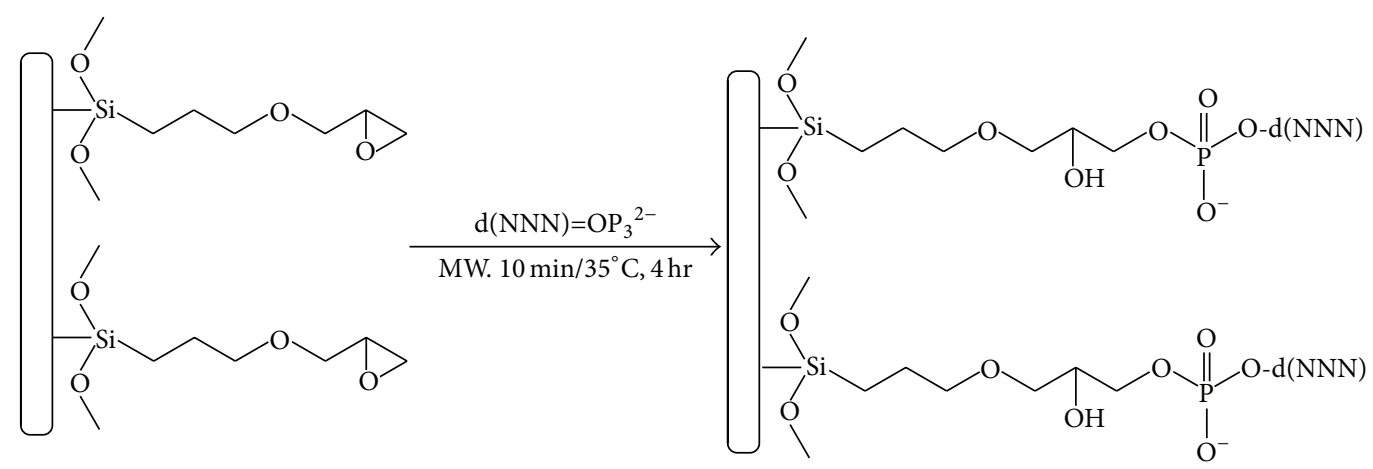

SCHEME 2: Covalent attachment of phosphorylated DNA.

various reports on the glass surface modification for the covalent attachment of biomolecules.

(1) Aldehyde Modification. For the aldehyde modification of the glass surface, the silanol groups on the surface are converted to an amine by different methods using amine modification reagents such as (3-Aminopropyl)triethoxysilane (APTES) [42]. Fixe et al. reported the aldehyde modification using glutaraldehyde. As shown in Scheme 1, the aminemodified surface is then treated with glutaraldehyde $(2.5 \%$ $\mathrm{v} / \mathrm{v}$ ) in $0.1 \mathrm{M}$ PBS for $2 \mathrm{~h}$ at room temperature. The slide is then washed with water and dried. The solution containing amine-modified DNAs is spotted on the slide and incubated in humidified chamber for up to $24 \mathrm{~h}$ to afford the DNA microarray. However, it is important to note that the unreacted aldehyde functional groups on the glass surface should be blocked by reacting them with the sodium borohydride $\left(\mathrm{NaBH}_{4}\right)$ [43].

Similar to the DNA immobilization, the cAb can also be immobilized on the aldehyde-modified glass surfaces to afford protein microarrays. However, the cAbs on the protein microarrays obtained by using aldehyde chemistry have a lower binding affinity as well as reduced specificity for the target antigens [44]. Another method of aldehyde modification of ester functionalized slide can be done by reduction to alcohol followed by controlled oxidation of alcohol to aldehyde using pyridinium chlorochromate (PCC) [45]. Apart from the glass chips surface, the glass bead surface is also modified to produce a surface with aldehyde functions using APTES and glutaraldehyde reagents [46].

(2) Epoxy Modification. Apart from silanization, epoxylation is a commonly used approach for glass surface modification. The epoxy functional group on the epoxy-modified glass surfaces are allowed to react with the amine-containing biomolecules for their immobilization [47]. Thus, the aminemodified DNAs and proteins with their native amine groups can be immobilized by this method on the glass surfaces for the generation of DNA microarray and protein microarray, respectively. As shown in Scheme 2, the epoxy functionalized surfaces can be used for the covalent attachment of phosphorylated DNAs.

The advantage of this method is that the $3^{\prime}$ phosphate group can make a covalent bond with epoxy groups. This allows immobilization of larger fragments of DNA or PCR products on the surface. As explained by Mahajan et al., the epoxylation of glass surface is carried out by keeping the glass in a $2 \%$ solution glycidoxypropyltrimethoxysilane (GOPTS) in toluene for $4-5 \mathrm{~h}$ at $50^{\circ} \mathrm{C}$ followed by washing and drying. After epoxylation of glass surface, the probe immobilization is done by spotting the $3^{\prime}$ phosphate DNA on the surface and microwave treatment for $10 \mathrm{~min}$ in a buffer of $\mathrm{pH} 10$. After the DNA immobilization, excess epoxy groups are masked by using capping buffer of $\mathrm{pH} 9$ containing $0.1 \mathrm{M}$ Tris with $50 \mathrm{mM}$ ethanolamine, for $15 \mathrm{~min}$ at $50^{\circ} \mathrm{C}$ [48].

One of the disadvantages of this approach is the need for high $\mathrm{pH}$ at which glass surface starts to degrade leading to the inconsistent results [49]. Furthermore, the high $\mathrm{pH}$ also damaged the native three-dimensional structure of proteins resulting in decreased sensitivity and increased nonspecific interactions.

(3) Carboxylate Modification. The amine-modified DNAs are commonly used because of the simple chemistry involved in their conjugation with fluorescence molecules with carbonyl functional groups. Same chemistry can be attributed to immobilizing the amine-modified DNAs on the carboxylic acid modified glass surface. The coupling between carboxylic acid and amine is direct without any linker in between them. The 1-ethyl-3-(3-dimethylaminopropyl) carbodiimide hydrochloride (EDC) is a commonly used reagent for amide coupling reactions. Other common coupling reagents are $\mathrm{N}$ hydroxysuccinimide (NHS), hydroxybenzotriazole (HOBt), and $\mathrm{N}, \mathrm{N}, \mathrm{N}^{\prime}, \mathrm{N}^{\prime}$-Tetramethyl-O-(benzotriazol-1-yl)uronium 


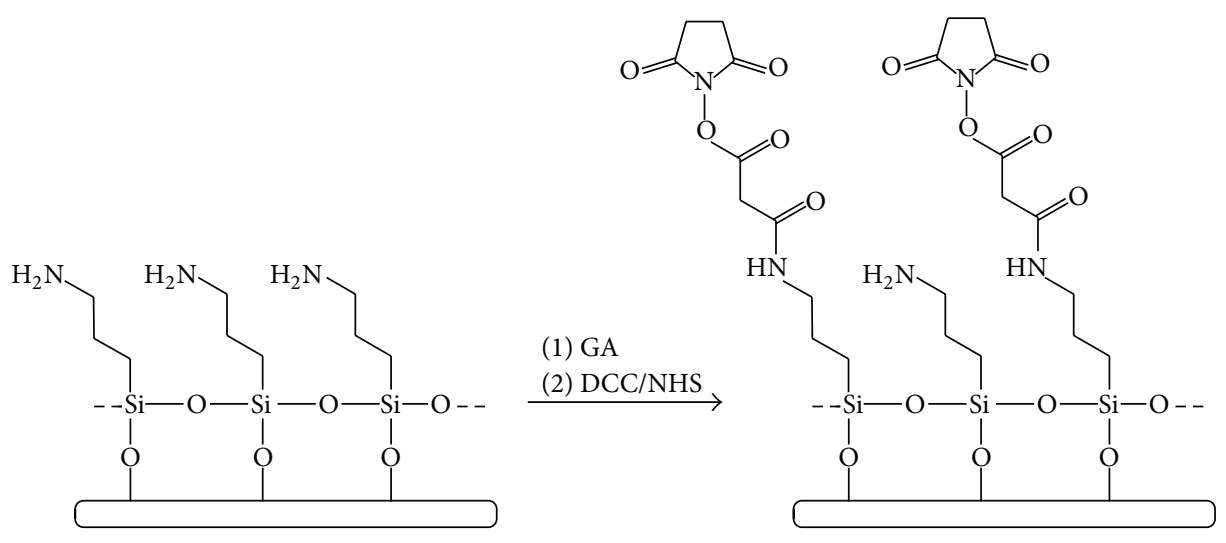

Scheme 3: Surface modification with activated carboxylic acid.

tetrafluoroborate (TBTU). The free amino functional groups in lysine containing proteins are targeted for the immobilization of proteins on the glass surface through amide coupling reactions. The polyamidoamine (PAMAM) dendrimer is used as a linker for immobilization of the DNAs on the glass surfaces [50,51]. PAMAM was initially invented in the 1980s to increase the amino groups on the outer surface of sphere [52]. Its application is now extended for DNA immobilization. Firstly, the silylation is performed using $95: 3: 2 \mathrm{v} / \mathrm{v}$ solution of ethanol, water, and APTES by treating the glass slides for $2 \mathrm{~h}$.

As depicted in Scheme 3, Benters et al. treated the silylated surface overnight with the solution of glutaric anhydride (GA) in DMF. Slides are then washed with DMF multiple times to remove the unreacted reagents. Carboxyl groups are activated by using activating reagent such as $1 \mathrm{mM}$ solution of NHS or dicyclohexylcarbodiimide (DCC) in DMF for $1 \mathrm{~h}$ followed by washing with DMF. For the covalent attachment of dendrimer, $100 \mu \mathrm{L}$ of $10 \%$ PAMAM in methanol is allowed to react with the activated carboxyl functional groups on the surface for $12 \mathrm{~h}$ at room temperature followed by washing with methanol to remove the excess dendrimer. Before the immobilization of DNAs on the surface, these dendrimers are activated by using GA/NHS as described above [53].

(4) Diazotization. Diazo, one of the stable bonds in organic chemistry, makes its use imperative in the surface modification process. For diazotization, the amine-modified surface is needed. Commonly, a cleaned glass using piranha solution for $30 \mathrm{~min}$ followed by deionized (DI) water is used [54]. The cleaned glass surface is then allowed to react with the (4-aminophenyl) trimethoxysilane in ethanol solution for $30 \mathrm{~min}$. After silanization, the amine-modified surface is treated with the sodium nitrite $\left(\mathrm{NaNO}_{2}\right)$ to generate diazobenzyl surface as depicted in Scheme 4. The diazotization reaction is done at $4^{\circ} \mathrm{C}$ using solution of $40 \mathrm{~mL}$ water, $80 \mathrm{~mL}$ $\mathrm{HCl}(400 \mathrm{mM})$, and $3.2 \mathrm{~mL} \mathrm{NaNO}_{2}(200 \mathrm{mM})$ as reported by Alwine et al. [55]. After the reaction, surface is washed with ice-cold sodium acetate buffer, deionized water, and ethanol. Then, the solution containing the probe DNAs is spotted on the ice-cold diazotized surface and air dried for 1-2h. Dolan et al. mentioned that the unreacted diazo groups on the surface are blocked by reaction with the glycine or UV-crosslinked followed by baking for two hours at $80^{\circ} \mathrm{C}$ [56]. The immobilized DNAs can be allowed to hybridize with the PCR products for the detection and discrimination of pathogens.

(5) Surface Modification with Supramolecules. In the last decade, tremendous work is done on the various applications of supramolecules, in particular, calixarenes $[31,57,58]$. The calix[4]crown- 5 derivatives are well known for their ability to capture the cationic substrates including metal cations and ammonium ions [59]. The cavities of calixarenes are well known to capture the amino groups of proteins and form stable complexes with them. According to the report, Lee et al. exploited the ability of calixarenes to form complexes with proteins to fabricate the protein microarrays on glass surfaces as depicted in Figure $4[60,61]$. For the fabrication of the protein microarrays, the calix[4]crown-5 derivatives containing aldehyde functional groups are reacted with the amine functional groups on the amine-modified glass chip to generate a monolayer.

Then, the protein in PBS solution, with 30\% glycerol is spotted on calix [4] crown- 5 derivative modified glass surface and incubated at $37^{\circ} \mathrm{C}$ for $3 \mathrm{~h}$. Then, the chip is washed with the $10 \mathrm{mM}$ PBS solution containing $0.5 \%$ Tween 20 for $10 \mathrm{~min}$ at room temperature and dried under a stream of $\mathrm{N}_{2}$ gas. The unreacted calix [4]crown- 5 derivatives, the free amine groups on the glass surface, are blocked by immersing the chip into the 3\% BSA in PBS solution for $1 \mathrm{~h}$ at room temperature.

Similar to protein microarrays [62], Nimse et al. reported the DNA microarrays based on the 9G technology, which uses the interactions of the monolayer of calix[4]arene derivatives on the glass surface and the DNAs appended to the nine consecutive guanines $(9 \mathrm{G})$ are also reported [32]. The aminocalix[4]arene (AMCA) derivative with aldehyde functional groups is allowed to react with the amine-modified glass surface to generate the AMCA slides. As depicted in Figure 5, the determination of contact angle of water on the AMCA modified glass surface indicates that the AMCA molecules make the glass surface hydrophobic.

Once the AMCA immobilization is done, the solution containing DNA probes appended to $9 \mathrm{G}$ is spotted on the 

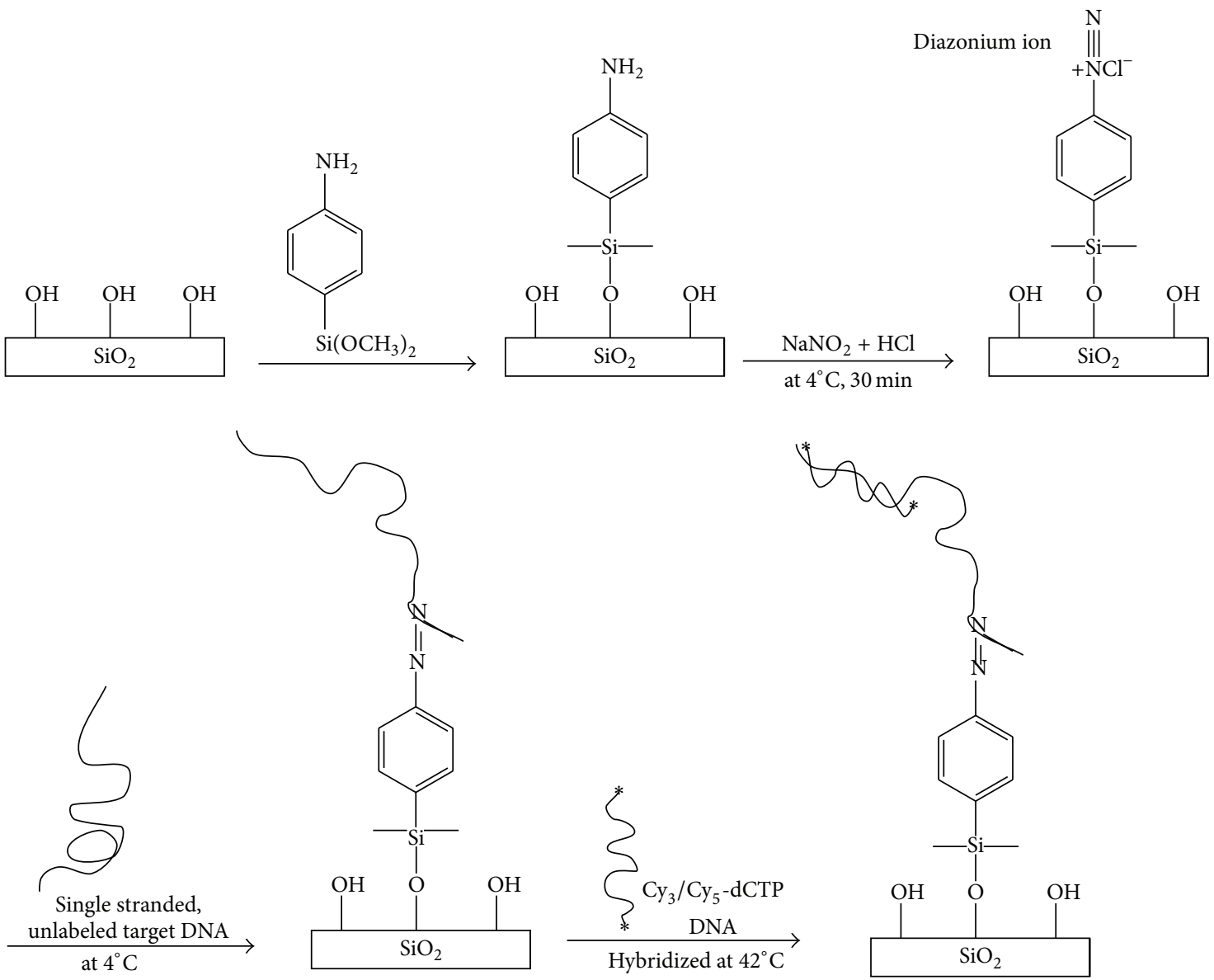

Scheme 4: Covalent immobilization of probe DNA on a glass surface by diazotization and subsequent hybridization.
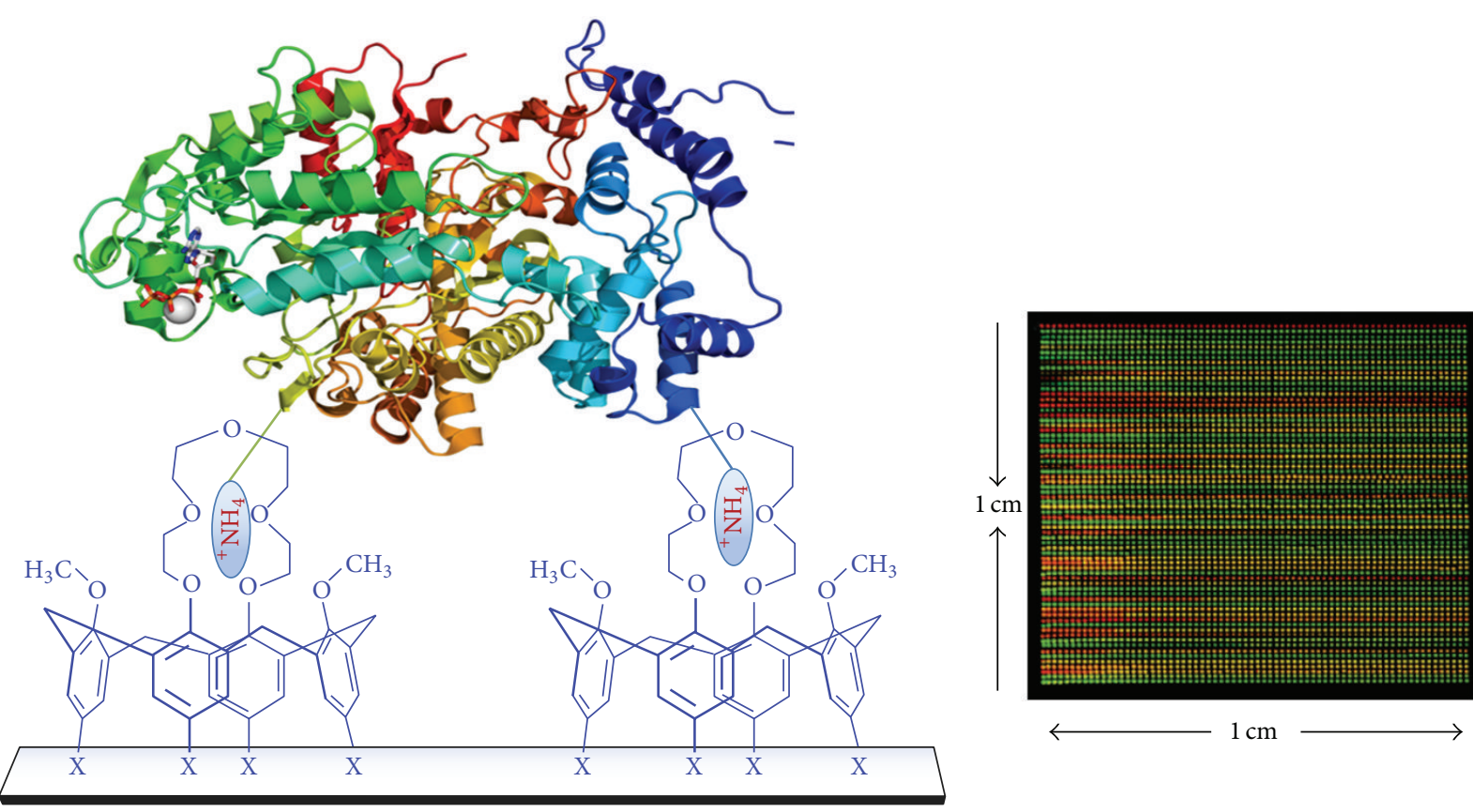

FIgURE 4: Interaction of calix[4]crown-5 derivative with proteins for the fabrication of protein microarray (adapted from [31]), 


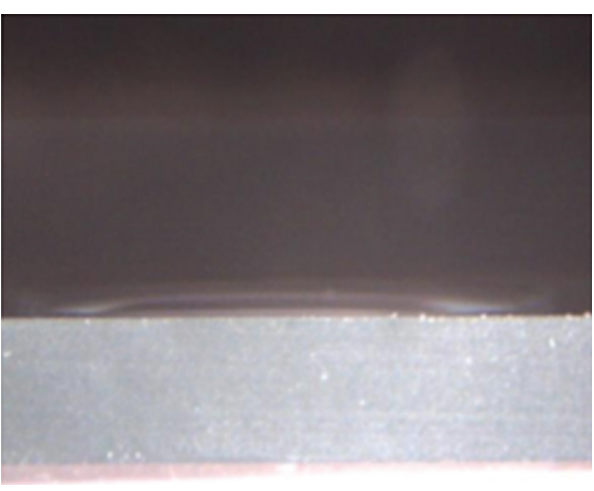

(a)

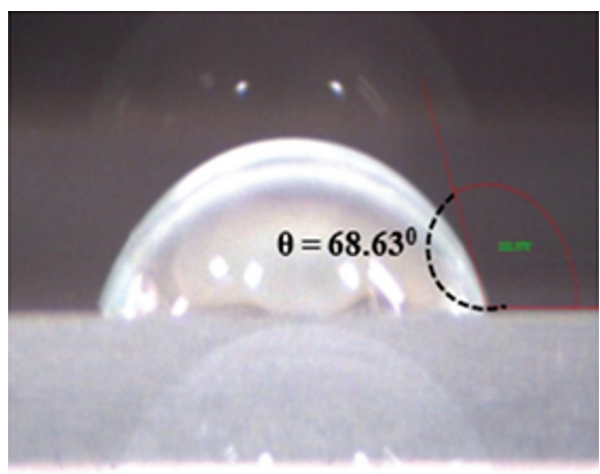

(b)

FIGURE 5: Contact angle comparison: (a) bare glass and (b) AMCA modified glass slide (adapted from [32]).

surface by using microarray. After incubation at room temperature for $4 \mathrm{~h}$, the slides are washed to remove excess DNAs and dried. The free AMCA molecules on the surface are then blocked with the $4 \mathrm{x}$ SSC solution containing BSA and 0.1\% SDS. Finally, the slides are dried to obtain 9G DNAChips $[63,64]$.

2.3. Carbon. In recent years, a nanoparticle-based structure like nanotubes and nanowires has got tremendous attention in biomedical and diagnostic fields $[65,66]$. Before 1991, $\mathrm{sp}^{3}$ hybridized form of carbon (diamond), $\mathrm{sp}^{2}$ hybridized forms like graphite, and C60 fullerene were the only known forms of carbon with potential applications [67]. In 1991, allotropes like carbon nanotubes (CNT) were first reported and successfully synthesized by Iijima with multiwall faces (MWCNT) [68].

Due to thermal, electrical, and magnetically unique properties, CNT became an important material in the development of biosensor platforms. Commonly reported method for preparation of CNT includes chemical vapour deposition $[69,70]$, arc discharge [71], and laser ablation [72].

Apart from CNT, other carbon-based nanostructures including carbon dots, carbon fibers, and PDMS also attracted researchers due to their diverse properties for biomolecule conjugation $[73,74]$. The major advantage of carbon nanomaterial is their large surface area which allows maximum space for biomolecule attachment.

Immobilization of protein, carbohydrate, and nucleic acid on the CNT surfaces allows various biological applications $[75,76]$. The most important part in biomolecule conjugation is the surface functionalization of carbon-based material. The general techniques for carbon surface modification are (physisorption) noncovalent and covalent modifications. There are several reports on the different techniques of surface modification of carbon-based surfaces. Due to the vastness of the research on carbon-based material, only few methods are described in this paper.

2.3.1. Physisorption. The hydrophobic character of CNT sidewalls and the strong $\pi-\pi$ interactions between the individual tubes causes them to aggregate and reduce their solubility in common solvents, which is considered as a problem for their biological applications. However, the same hydrophobic character of the CNT surface is exploited for fabrication of biosensors by immobilizing biomolecules onto the CNT surfaces through hydrophobic-hydrophobic interactions [77-79].

The advantage of noncovalent interaction is a limited distortion of the three-dimensional structure of a protein or enzyme to be immobilized. The hydrophobic amino acids in proteins and enzymes develop the $\pi-\pi$ interactions with the hydrophobic part of CNT, which make them adsorbed on the surface of CNT [80-83]. As mentioned earlier, the platforms modified by noncovalent interactions suffer from the typical drawbacks of nonspecific interactions resulting in the decreased specificity and sensitivity of a biosensor.

To eliminate the problem of nonspecific interactions of target proteins with the sensor surface, the novel approach of polyethylene oxide (PEO) polymer coating is adopted by many researchers. The PEO is well known for its protein repelling ability [84]. Bomboi et al. reported the use of Tween 20 which is composed of three PEO branches and P103, another molecule with hydrophobic polypropylene oxide units, to modify the surface of CNT before adsorption of proteins on it. The surface of Tween 20 and P103 modified CNT becomes slightly hydrophilic compared with bare CNT, which results in the decrease in its interaction with the hydrophobic amino acid chains of biomarker proteins [85].

As depicted in Figure 6, for the selective immobilization of streptavidin on the CNT surface, Chen et al. used mixed noncovalent and covalent approach, which allows the highly specific immobilization of streptavidin and blocks the nonspecific binding of other proteins like BSA [33].

Conjugation of a fluorescent molecule on the CNT surface is an immerging technology for highly sensitive detection of biomolecules. Nakayama-Ratchford et al. reported the immobilization of the fluorescent molecules like fluorescein on the surface of CNT through $\pi-\pi$ interactions [86]. There are several reports on the applications of CNT surfaces modified with the fluorescent molecules through noncovalent interactions [87-90].

2.3.2. Chemical Modification. To prevent the nonspecific binding and to avoid the leaching of biomolecules from the 


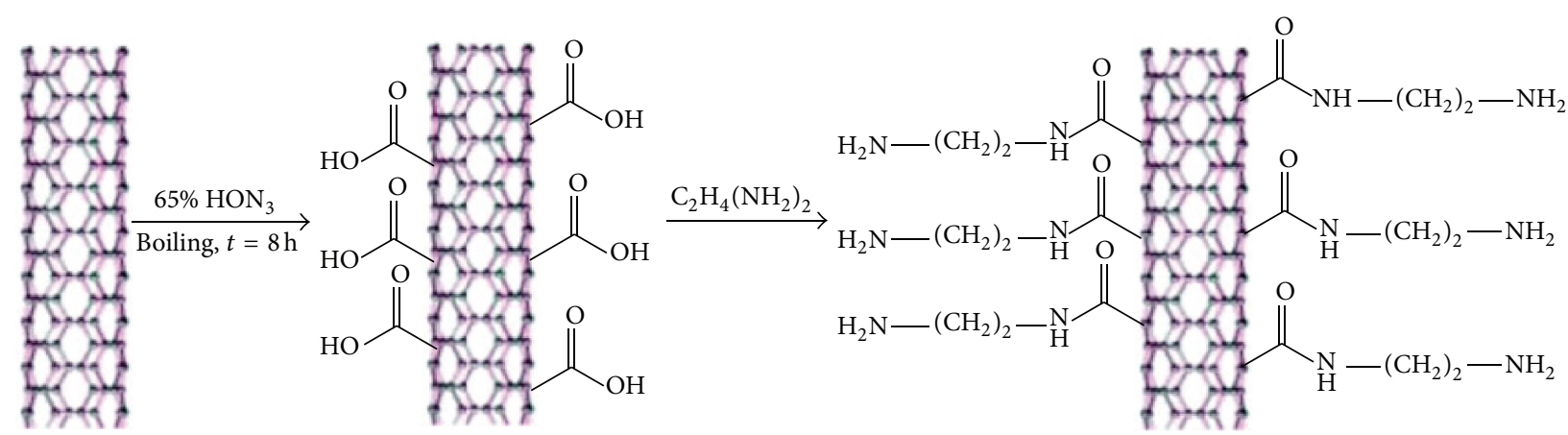

Scheme 5: Amine modification of CNT.

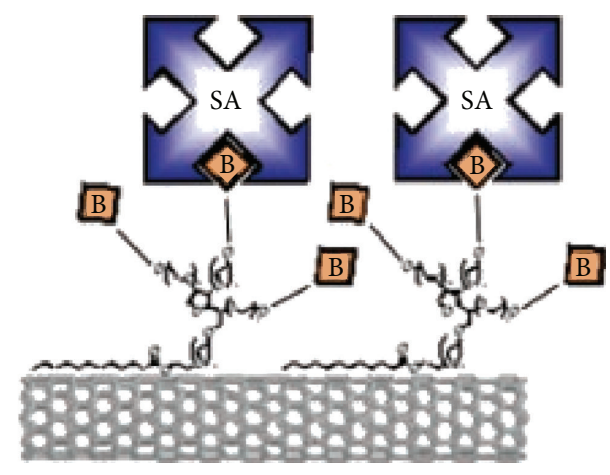

FIGURE 6: Streptavidin recognition by a nanotube coated with biotinylated Tween (adapted from [33]).

CNT surface, a covalent modification technique is reported. There are two types of covalent modifications, namely (i) indirect method, for example, carboxylation of CNT surface, and (ii) direct method, for example, fluorination of CNT surface where surface carbons change from $\mathrm{sp}^{2}$ to $\mathrm{sp}^{3}$ hybridization. Esterification or amidation and sidewall covalent attachment are other approaches for covalent attachment [91, 92].

(1) Carboxyl Modification. The modification of the sensor surfaces with the carboxyl groups is a general and highly used surface modification method. Once the surface is modified with the carboxyl groups, it can be converted to a variety of functional groups through reaction with appropriate reagents. Furthermore, the carboxylated surfaces can be directly conjugated with proteins or DNA through their amine functional groups using coupling reagents. A mixture of sulphuric acid and nitric acid is a commonly used reagent for the carboxylation of CNT surface.

Marshall et al. reported the method for carboxyl modification of CNT [93]. According to this method, a $2 \mathrm{mg}$ sample of SWCNT is added to the $75 \%$ mixture of concentrated sulphuric acid and nitric acid $(1 \mathrm{~mL})$. The mixture is allowed to sonicate in sonicator at $20^{\circ} \mathrm{C}$. The reaction mixture is then diluted to $250 \mathrm{~mL}$ by using deionized water. The carboxylated CNTs are then filtered through polytetrafluoroethylene filter (PTFE) of $0.45 \mu \mathrm{m}$ size. Finally, the collected nanotubes are washed with water at acidic $\mathrm{pH}$ followed by ethanol and dried in a vacuum desiccator.

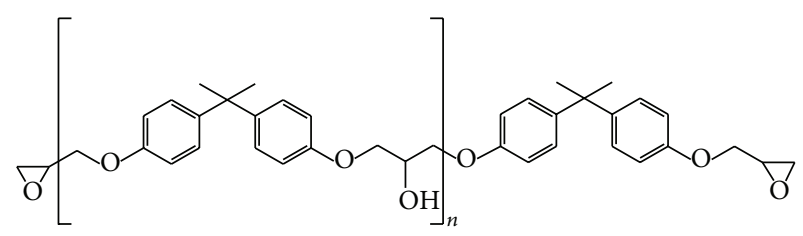

FIgURE 7: Structure of Epon resin 828.

(2) Amine Modification. Amide coupling is the most commonly used conjugation technique in biomolecule attachment. Either the amine or acid part of DNA or protein can be used for conjugation using amide coupling reaction. For the conjugation of DNA to CNT through its phosphate group, amine modification is needed.

Tam et al. reported the DNA sensor based on the amine modification of MWCNT as depicted in Scheme 5 [94]. The MWCNT were boiled in the $15 \mathrm{M}$ nitric acid for $12 \mathrm{~h}$ to generate the carboxylated MWCNT. The purified carboxylated MWCNT were reacted with ethylenediamine to obtain the amine-modified MWCNT. The amine-modified MWCNT were conjugated to DNA by using EDC coupling reaction.

Other reports for amine modification of CNT include the use of nitric acid and sulphuric acid mixture for carboxylation of the surface followed by ethylenediamine reaction [95]. There are several reports on the covalent conjugation of fluorescent molecules to the CNT surfaces [96-98].

(3) Epoxy Modification. Epoxide group is a highly reactive functional group used in many substitution reactions as an electrophile. Eitan et al. reported the covalent attachment of epoxide-terminated molecules to carbon nanotubes by reaction between epoxide rings and carboxylic acid groups that are initially formed on the nanotube surface [99]. For epoxidation of CNT, the surface is first carboxylated by dispersing the CNT in 75\% solution of sulphuric acid in nitric acid for $3 \mathrm{~h}$. The purified carboxylated CNT were kept in the acetone with sonication for $1 \mathrm{~h}$. Then, the solution containing the carboxylated CNT is mixed with the solution of Epon resin 828 (Figure 7) in acetone to allow the reaction between Epon resin 828 and carboxyl groups on the CNT surface as depicted in Scheme 6. 


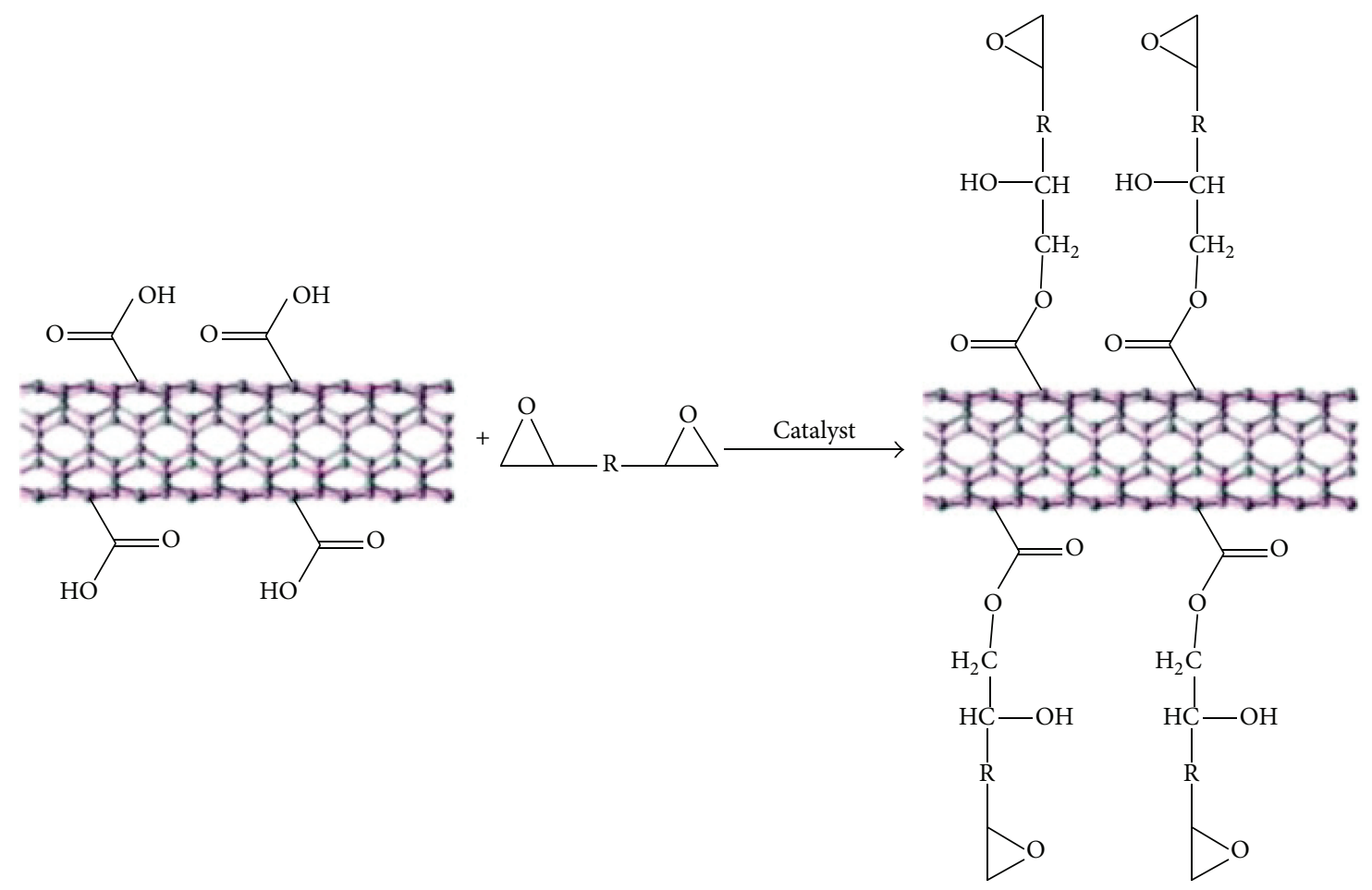

SCHEme 6: Epoxy modification of CNT.

The mixture of solutions is sonicated for $1 \mathrm{~h}$ followed by stirring and heating at $70^{\circ} \mathrm{C}$. The reaction was quenched by addition of appropriate amount of potassium hydroxide. Then, the epoxilated CNT were purified and a number of epoxy groups on the CNT surface were determined by using thermogravimetric analysis.

2.4. Nitrocellulose. A PoC diagnosis system is always expected to deliver final results in few minutes. Though the microarrays based on the glass and gold surfaces are useful for detection of multiple analytes at a time, they need longer time for final data interpretation. Microfluidic systems based on paper or nitrocellulose membranes are emerging surfaces for detection of bacteria, viruses, and proteins. A paper is advantageous due to its hydrophilic nature which allows the aqueous solutions to penetrate without the need of any external force [100]. The essential constituent of paper is cellulose. The cellulose has hydroxyl functional groups which can be modified and changed according to surface properties needed for a particular detection device [101]. Due to low cost and high availability, paper is preferred for large scale production. Moreover, the devices required for the tests are portable and disposable [102-105]. The very first example of paper based detection is glucose detection in urine [106] and pregnancy test kit [107]. There are different types of paper like Whatman ${ }^{\circledR}$ filter paper, glossy paper [108], membrane, and so forth. Whatman filter is used because of its high penetration and flow rate [109-112], but in some cases, it does not have the necessary characteristic for surface modification. Membranes, on the other hand, are planner sheets and provide larger surface area for immobilization of biomolecules such as DNA and protein. The nitrocellulose (NC) membrane is broadly used for immobilization of DNA [113], protein [114], and enzymes [115] due to its hydrophobic surface.

2.4.1. Physical Adsorption. Single-stranded DNAs are irreversibly bound to the surface of the NC membrane with noncovalent interactions. The primary interactions are hydrophobic and electrostatic between the positively charged surface of the membrane and negatively charged DNAs. The nitrocellulose offers very high binding capacity for DNAs and proteins. Fabrication of NC membranes can be done by different methods including the photolithography. The wax patterning method is fast, cheap, and easy to process and does not need organic solvents. The NC membranes with the pore size of $0.45 \mu \mathrm{m}$ do not need pretreatment for penetration. The fabrication process includes mainly printing and baking steps which can be finished in $10 \mathrm{~min}$. As shown in Figure 8, firstly, the wax is printed on the surface of NC membrane and baked at $125^{\circ} \mathrm{C}$ for $5 \mathrm{~min}$ in the oven. The melting of the wax on membrane makes it more hydrophobic and affords surface suitable for the immunoassay. For immunoassays, Lu et al. coated the cAbs on the surface, and the free area is blocked with the $1 \%$ BSA.

During baking, melted wax passes through the membrane. The $121^{\circ}$ contact angle of backside membrane assures the melting of wax thoroughly. The efficiency of wax treated membrane is compared with the untreated membrane by immobilizing fluorescence labeled goat antihuman IgG. The immobilization on wax printed surface is more uniform than the untreated membrane. Apart from this, a large volume of liquid can be used because ring effect of protein on the 


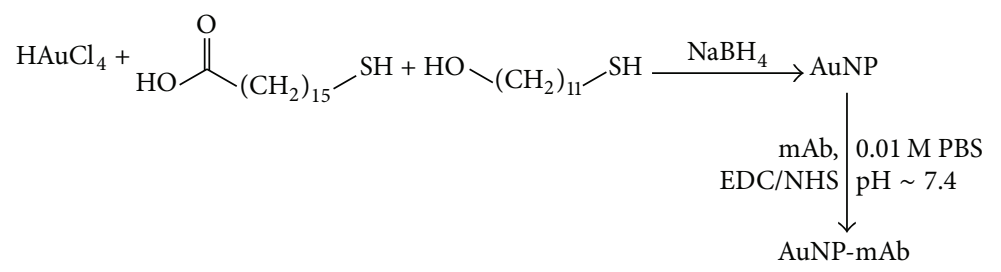

Scheme 7: Immobilization on antibodies on AuNP.

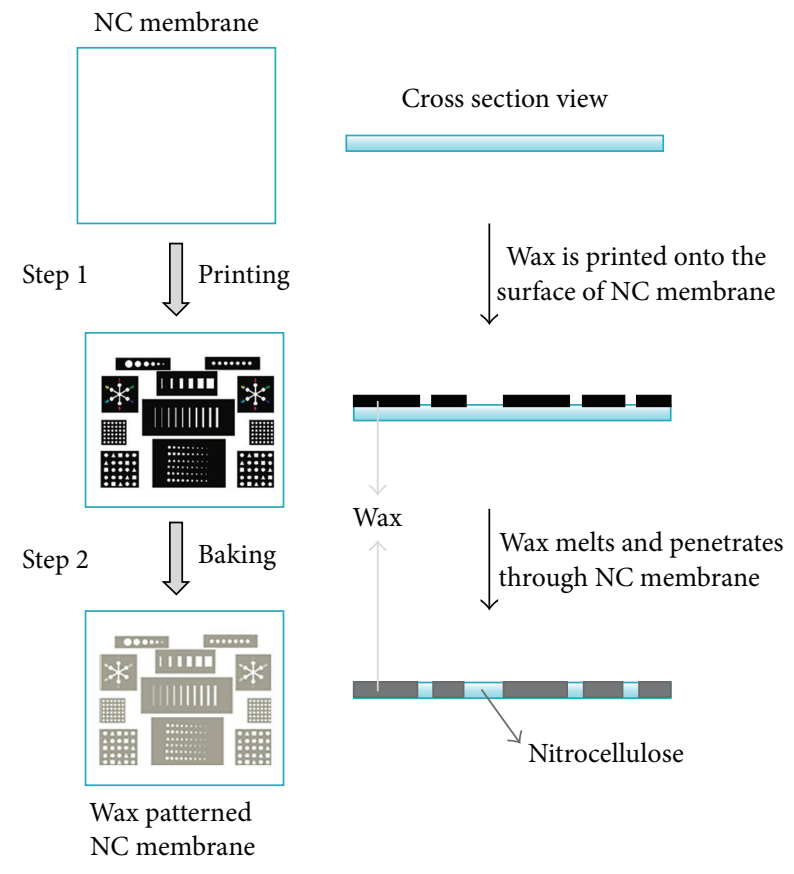

FIGURE 8: Wax printing on nitrocellulose membranes (adapted from [34]).

untreated membrane is avoided. Wax printing method generates $100 \mu \mathrm{m}$ microchannel, which removes the micrometer size contaminants and makes the wax printed membranes suitable for the applications in microfluidic assays. Apart from immobilization, wax printing has application in dot immunoassay and sample purifications [34].

Due to advantages of NC membrane for high binding capacity and good flow of solution, it is also used on the chip surfaces. The glass slide can be coated with the $12 \mu \mathrm{m}$ layer of $\mathrm{NC}$ to afford a platform with the intrinsic properties of NC. The solution of cAbs in PBS buffer containing 10\% glycerol is then spotted on the modified surface. After spotting, the slides are incubated for one hour. After incubation, slides are washed with $0.1 \%$ Tween 20 in PBS buffer and dried to generate the platform for detection of biomarker proteins [116].

Apart from routine microarray applications, NC membrane is also used for the detection of circulating tumor cells (CTC) as reported by Zhang et al. The binding of CTCs by the cAbs immobilized on the NC membrane is detected by Surface Enhanced Raman Scattering (SERS), as depicted in Figure 9.
Usually, the antibodies specific for cancer cells are used as a capture substrate and immobilized on the surface. The $\mathrm{NC}$ membrane is cut into $1 \mathrm{~cm} \times 1 \mathrm{~cm}$ pieces. Then, these pieces are immersed in the ethanol and then tiled on the PMMA wafer. After washing, the membrane is activated by using PBS buffer containing antibodies at $37^{\circ} \mathrm{C}$ for $30 \mathrm{~min}$. During this process, the cAbs are avidly immobilized on the NC membrane. The $1 \%$ BSA solution is loaded to block the free surface area to avoid any background signals due to nonspecific interactions. Finally, the membranes are washed with PBS buffer and stored at $4^{\circ} \mathrm{C}$. The gold nanoparticle and Raman probes are used to detect the CTCs by SERS [35].

2.5. Gold. Application of nanoparticles is a most focused area in the field of inorganic chemistry and it has also attracted imaginations of many biologists too. Inorganic nanoparticles including gold, silver, and ferrous oxides have found many important applications in cell signaling, drug delivery, and colorimetric and fluorescence-based detections. Gold nanoparticles (AuNP) functionalized with proteins, DNAs, or Raman probes are well known in the field of biosensors and nanobiotechnology for their applications in the molecular diagnostics [117-119], protein detection [120-122], gene regulation [123], and cell imaging [124].

\subsubsection{Covalent Modification}

(1) Thiol Based Modification. AuNPs are commonly used in the electrochemical and optical detection systems. The conjugation with biomolecule does not change the optical properties of AuNP [125]. Di Pasqua et al. reported thiol modification for the detection of E. coli O157:H7, E. coli specific antibodies were conjugated with the AuNPs [126]. As shown in Scheme 7, the $10 \mathrm{~nm}$ AuNPs are carboxylated and then coupled to E. coli specific monoclonal antibody (mAb) through amide coupling.

For the generation of AuNPs, to the solution containing $410 \mathrm{mg}$ of $\mathrm{HAuCl}_{4} \cdot 3 \mathrm{H}_{2} \mathrm{O}$ in $6 \mathrm{~mL}$ of water, ethanoic solutions of 11-mercapto-1-undecanol and 16-mercaptohexadecanoic acid are added. Upon addition of $\mathrm{NaBH}_{4}$ to this mixture at $0^{\circ} \mathrm{C}$, the solution turns brown. The product AuNP capped with alkanethiol pendant alcohol and carboxylic acid functional groups precipitate upon three hours of stirring. The precipitated particles are then thoroughly washed with ethanol and an ethanolic solution containing a small amount of $1 \mathrm{M} \mathrm{HCl}$. The AuNPs are then dried under vacuum for ten hours. For the conjugation of mABs with the AuNPs, the carboxylic acid functional groups on the AuNPs are 

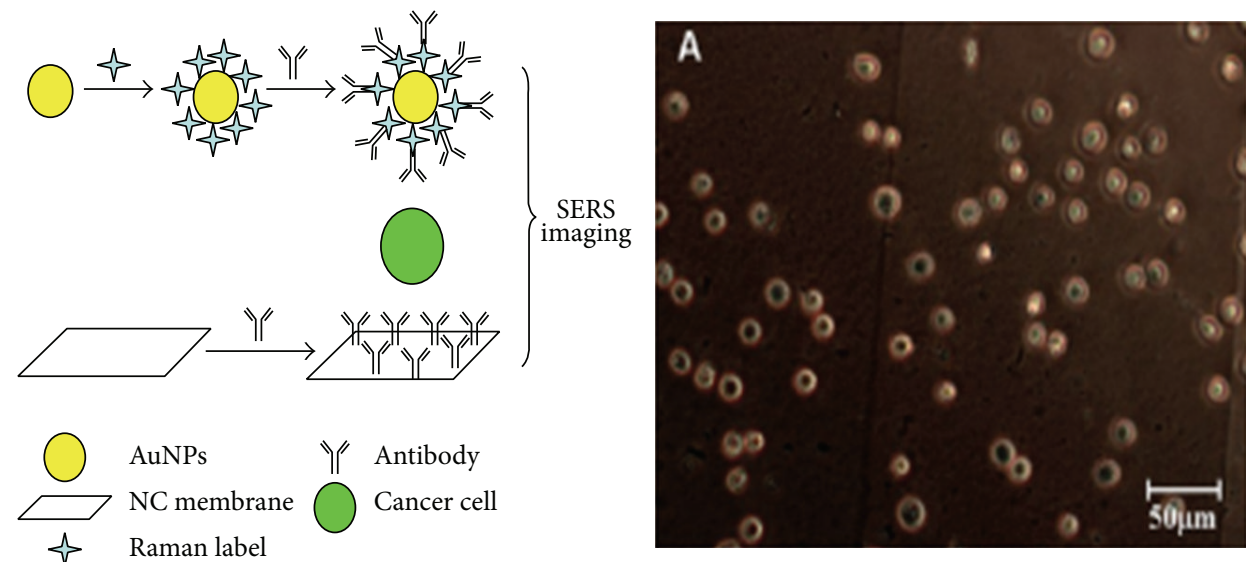

FIgURE 9: Detection of circulating tumor cells on NC membranes containing immobilized cAbs (adapted from [35]).

activated by reacting the AuNPs with 1-ethyl-3-3(3-dimethylaminopropyl) carbodiimide hydrochloride (EDC) and Nhydroxysuccinimide (NHS) in the PBS buffer. The mABs are then added to this solution, and the suspension is stirred at room temperature for $30 \mathrm{~min}$. The $\mathrm{mAB}$-conjugated AuNPs are then collected by centrifugation and washing with PBS and ethanol. The mAB-conjugated AuNPs successfully bind to $E$. coli when incubated in PBS at $\mathrm{pH}$ 7.4. In other reports, the AuNPs were found very effective in the detection of cancerous pancreatic cells.

The AuNPs are known to suffer from the problem of aggregation upon long-term storage. Therefore, to solve this issue, the AuNPs are conjugated with the polyethylene glycol (PEG) to prevent their aggregation $[127,128]$. The conjugation of PEG with the AuNPs makes the later hydrophilic, thus preventing agglomeration induced by hydrophobic interactions. A PEG with the heterobifunctional groups (dithiol at one end and a carboxyl at another end) is coated on the AuNP. The dithiol group allows stable anchoring heterobifunctional PEG ligands on the surface of AuNP, and the terminal carboxyl group is used for coupling with antibodies. The carboxyterminated bifunctional PEG linker is synthesized by following a method reported by Eck et al. which is depicted in Scheme 8 . The anionic polymerization of compound 1 with an excess of ethylene oxide allows synthesizing compound $\mathbf{2}$. The treatment of compound 2 with chloroacetic acid at $60^{\circ} \mathrm{C}$ allows generating compound 3 . The reaction of an excess of the elemental bromine in dichloromethane at $0^{\circ} \mathrm{C}$ for four hours in the dark with compound 3 produces dibromide compound 4 . Compound 5 is obtained by reaction with compound 4 in water with the excess of sodium hydrosulfide hydrate.

The synthesized bifunctional PEG linker is then conjugated with the citrate-stabilized gold nanoparticles by simple ligand exchange. The citrate-stabilized gold nanoparticles are known to aggregate in the buffer containing salts. Therefore, the ligand exchange from citrate to PEG should be done in pure water. The PEGylated AuNPs are conjugated to monoclonal F19 antibodies for the detection of human pancreatic carcinoma through EDC/NHS coupling reaction [129].

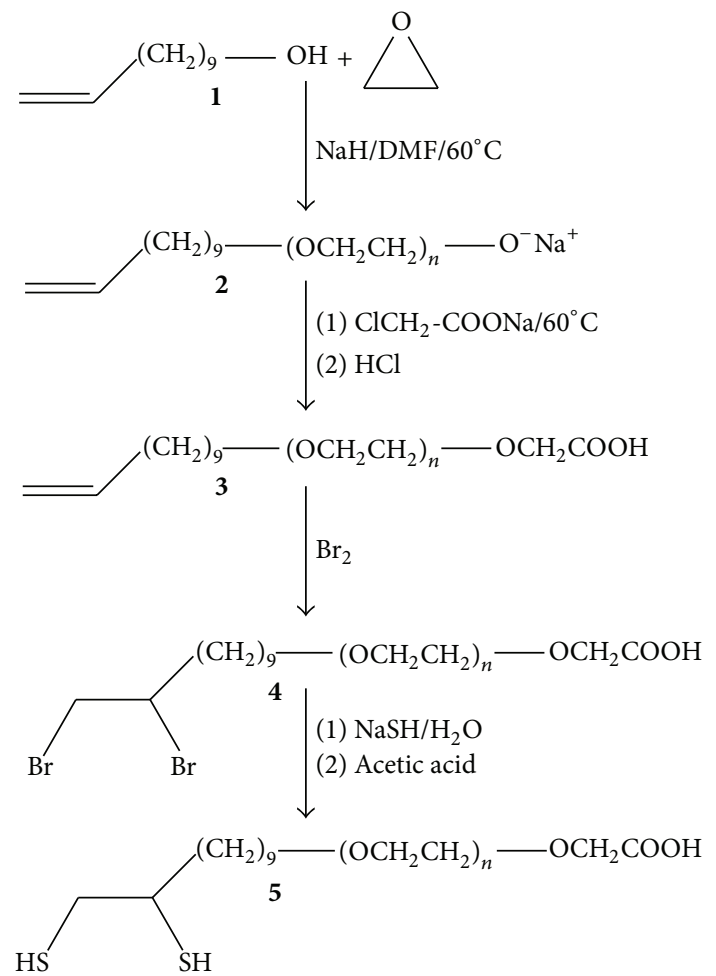

Scheme 8: Synthesis of bifunctional PEG linker using conjugation with AuNP.

(2) Hydrazide Modification. According to the report by Zhi et al., the hydrazide-derivatized self-assembled monolayer on a gold surface is used for the efficient and selective anchoring of oligosaccharide [39]. The generated oligosaccharide microarrays allow the fluorescence-based detection of target proteins. The use of gold as a substrate for the fluorescencebased detection suffers from the drawbacks including fluorescence quenching and nonspecific surface adsorption of proteins. However, the use of $\omega$-thiolated fatty acid $\left(\mathrm{C}_{16}\right)$ selfassembled monolayer between the gold surface and hydrazide 

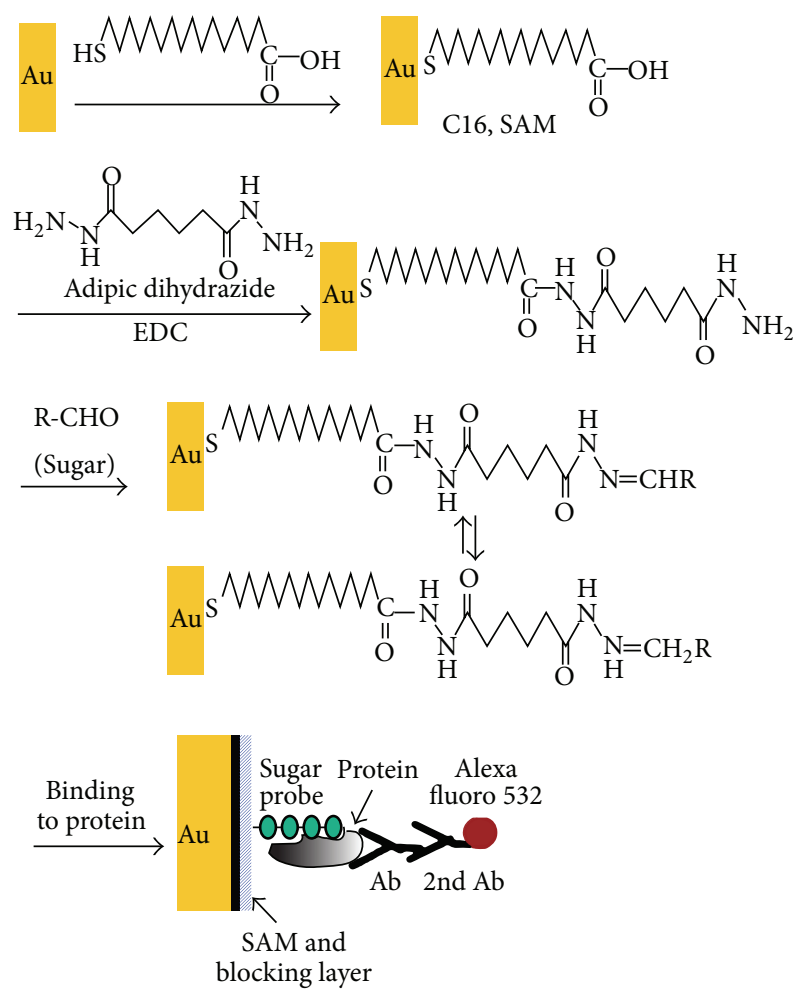

Scheme 9: Application of hydrazide-derivatized SAM on a gold surface for the fabrication of oligosaccharide microarray (adapted from [39]).

groups minimizes the quenching effect. Moreover, the effective blocking of the surface with the poly(ethylene glycol) aldehyde and BSA reduces the nonspecific adsorption of protein on the surface.

For the fabrication of the reported oligosaccharide microarrays, the gold substrate is prepared by following a method depicted in Scheme 9. The self-assembled monolayer (SAM) of 16-mercaptohexadecanoic acid (MHDA) is obtained by soaking the gold coated slides in the isobutyl alcohol for 2 days. The slides are then washed in ethanol to remove excess reagents and are dried under the nitrogen stream. The carboxyl functional groups on the SAM are converted to the hydrazide groups by incubation of the SAM covered slides in the dimethyl sulfoxide solution containing 1-ethyl-3-(3-dimethylaminopropyl) carbodiimide and adipic dihydrazide. The ethanol-washed and dried slides are then used for the oligosaccharide printing to obtain oligosaccharide microarrays.

The generated oligosaccharide microarray platform allows interrogation of carbohydrate-protein interactions in a high-throughput manner.

2.6. Silver. Similar to AuNPs, silver nanoparticles (AgNP) are also used for the immobilization of proteins and enzymes. The surface of AgNP allows adsorption of proteins. Hence, it can be utilized as a host matrix for various biomolecules. Silver is a suitable substrate for the immobilization of whole cell or the isolated enzymes $[130,131]$.

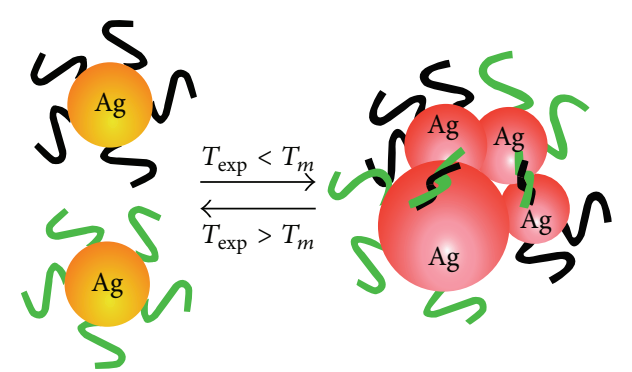

Figure 10: AgNPs-oligonucleotide conjugates (adapted from [36]).

2.6.1. Electrostatic Modification. The electrostatic interactions allow the physical adsorption of biomolecules on the surface of AgNPs. Shen et al. reported that the AgNPs are synthesized by reduction of silver nitrate in the presence of sodium citrate. During the reduction process, the solution is sonicated for $15 \mathrm{~min}$ to obtain the yellow silver colloid which is then kept at $4^{\circ} \mathrm{C}$ for several days, away from light. Then, isolated nanoparticles can be used for physisorption of proteins at a $\mathrm{pH}$ higher than their isoelectric point [132].

2.6.2. Covalent Modification. As depicted in Scheme 10, the AgNPs prepared by the citrate reduction method and stabilized with citrate [133] can be functionalized with carboxyl groups upon treatment with 3-mercaptopropanoic acid (MPA). As reported by the Petkova et al., for the immobilization of alcohol dehydrogenase from Thermoanaerobium brockii ( $\mathrm{TbADH})$, the carboxyl-modified AgNPs were treated with the solution containing $\mathrm{TbADH}$ under continuous stirring for $7 \mathrm{~h}$ at $26^{\circ} \mathrm{C}$, a research by [134]. The AgNPs modified with the TbADH were successfully used for the biotransformation studies.

The application of a bifunctional linker for the modification of AgNPs is reported $[135,136]$. The bifunctional linker, 11-mercaptoundecanoic acid, was used with 1-octanethiol in $1: 1$ ratio to generate the mixed SAM on the surface of AgNP. The IgG antibodies are then conjugated with the mixed SAM modified AgNPs. It is reported that, upon covalent conjugation of biomolecules with AgNPs, their stability and activity is maintained [137].

According to another report on the covalent modification, AgNPs-oligonucleotide conjugates are prepared by using DNA and triple cyclic disulfide moieties [36]. As depicted in Figure 10, the two types of AgNPs-oligonucleotide conjugates with complementary DNA sequences undergo DNA hybridization driven coagulation, resulting in the color change.

As depicted in Figure 11, the AgNP-DNA conjugates were prepared by treatment of AgNPs with the cyclic disulfide modified oligonucleotide. The AgNP and oligonucleotides were allowed to react with each other with $1: 4$ ratio in the presence of $1 \%$ sodium dodecyl sulfate and $\mathrm{NaCl}$. The overnight incubation of solution results in the AgNP-DNA conjugates which are collected by centrifugation and washed to remove the excess DNAs. 


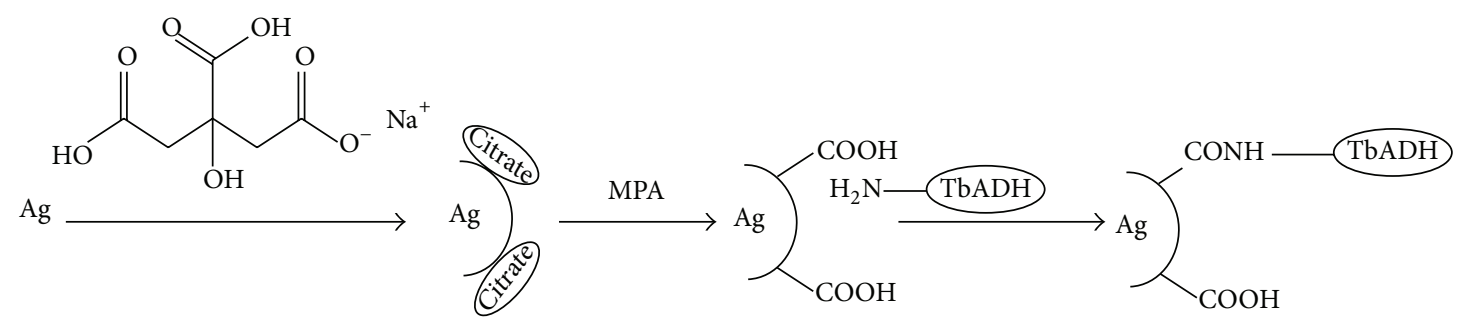

Scheme 10: Covalent conjugation of enzymes on the surface of carboxyl-modified AgNPs.

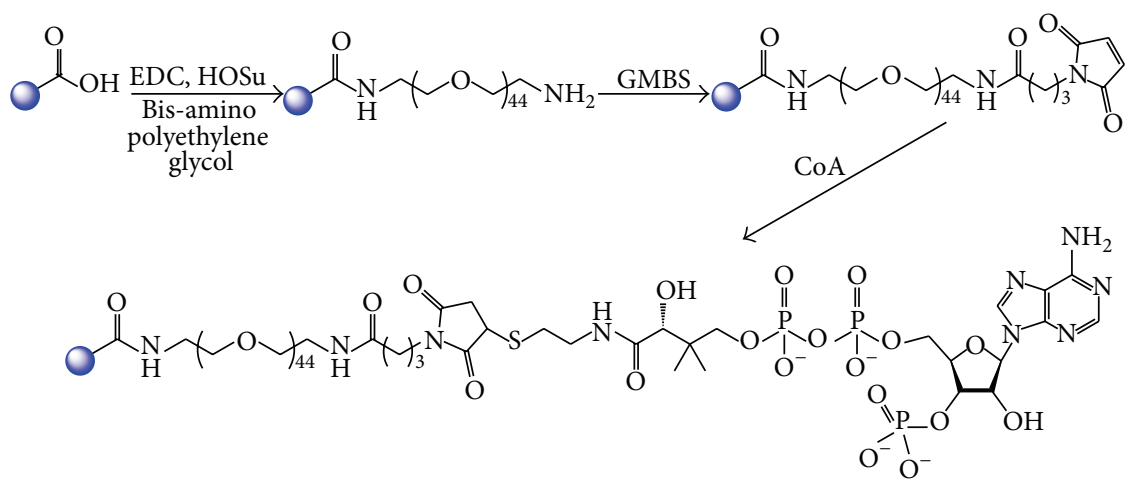

SCHEME 11: Covalent conjugation of coenzyme A to polystyrene nanoparticles.

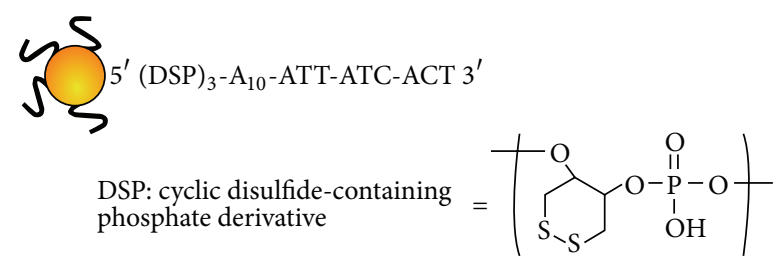

FIGURE 11: Conjugation of AgNPs with oligonucleotides by using DSP as a linker molecule (adapted from [36]).

2.7. Polystyrene. Polystyrene is an aromatic polymer obtained by polymerization of styrene monomers [138]. The polystyrene-based NPs are widely used in the molecular diagnostics for the detection of biomarker proteins and genomic DNAs. Polystyrene can be employed as a coating on a variety of nanoparticles as its functional groups can be easily modified or conjugated with other molecules. The other application of polystyrene is in the fabrication of fluorescence beads (FBs). The fluorescence molecules are loaded into the polystyrene shell to produce FBs, which are then used in various sensing applications. The polystyrene is also used to coat the magnetic NPs so they can be conjugated with other biomolecules such as DNA and Proteins. The applications of polystyrene include but are not limited to the detection of E. coli [139], the detection of cardiac Troponin T (cTnT), the detection of Herpes simplex virus, and many more.

2.7.1. Covalent Modification. Covalent modification through carboxyl group is well known for modification of biomolecule.
Most of the polystyrene-based nanoparticles bear large numbers of pendant carboxyl which increases the loading amount of biomolecule.

Enzyme catalyzed covalent immobilization of the proteins bearing a small 12-mer "ybbR" tag onto the polystyrene nanoparticles (PSNP) is recently reported by Wong et al. [140]. As depicted in Scheme 11, the carboxyl-PSNPs were reacted with the bis-amino-polyethylene glycol in the presence of HOSu and EDC to generate the amino-pegylated PSNPs. These PSNPs are then reacted with the g-maleimidobutyric acid succinimidyl (GMBS) to obtain maleimidefunctionalized PSNPs. The maleimide-functionalized PSNPs upon chemoligation with coenzyme $\mathrm{A}(\mathrm{CoA})$ produce the CoA-derivatized PSNPs.

As depicted in Scheme 12, the protein of interest bearing ybbR-tag is immobilized on the CoA-derivatized PSNPs. The phosphopantetheinyl transferase (Sfp) catalyzed the reaction between the serine residue of the ybbR-tag and the phosphopantetheine moiety of CoA with the simultaneous loss of $3^{\prime}, 5^{\prime}$-adenine diphosphate results in the attachment of proteins onto the surface of PSNPs. It is reported that the enzymes immobilized by this method retain their activity.

There are several reports on the use of fluoromicrobeads for the detection of biomarkers. Primarily the fluoromicrobeads are made up of carboxylated polystyrene as a coating material entrapping the fluorescent molecules. According to the recent report by Song et al. [37], the fluoromicrobeads were used for the detection of the cTnT on the protein microarray as depicted in Figure 12.

The carboxylate modified fluoromicrobeads were conjugated with the anti cTnI mAb through EDC/NHS-mediated 

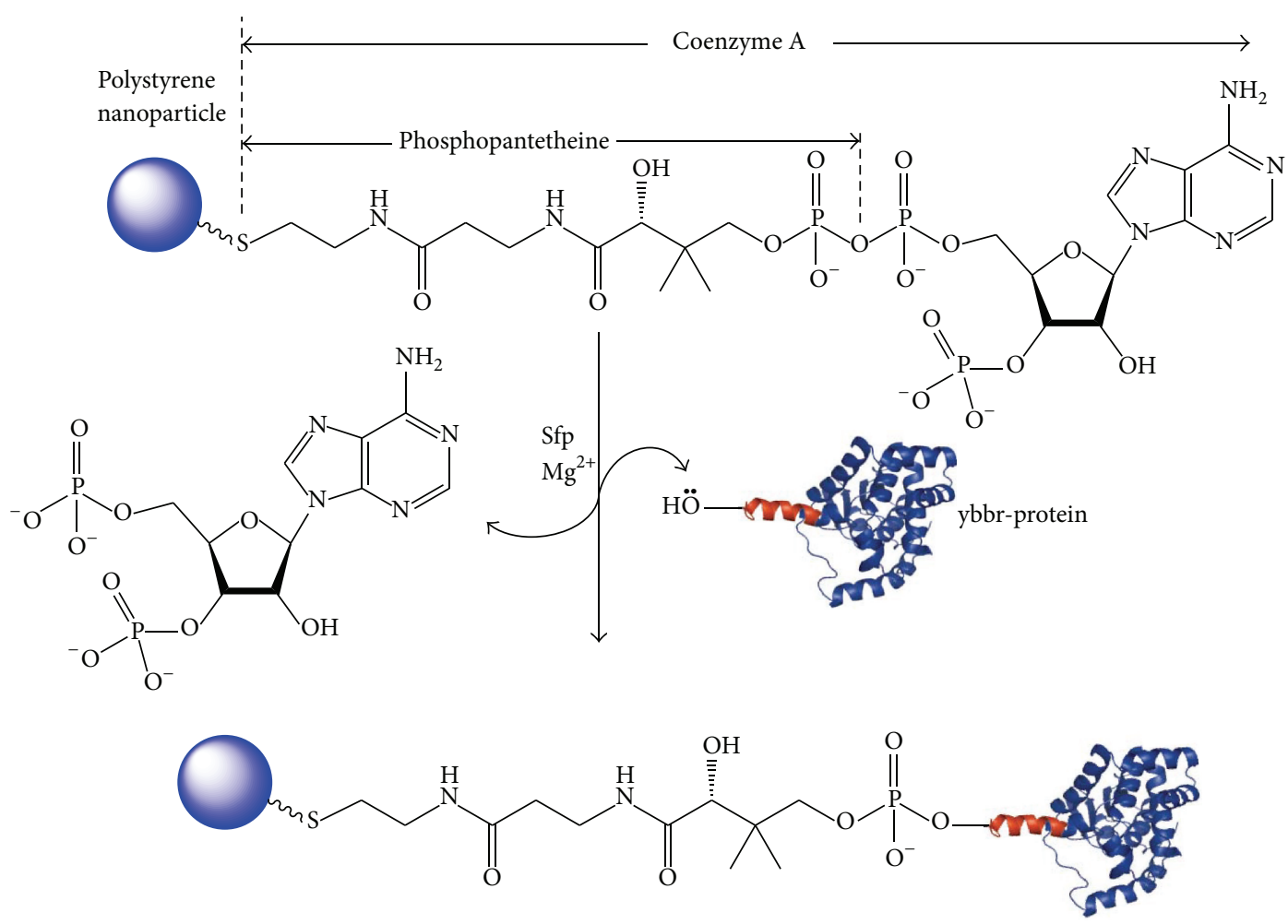

SCHeme 12: Protein conjugation to polystyrene NP.

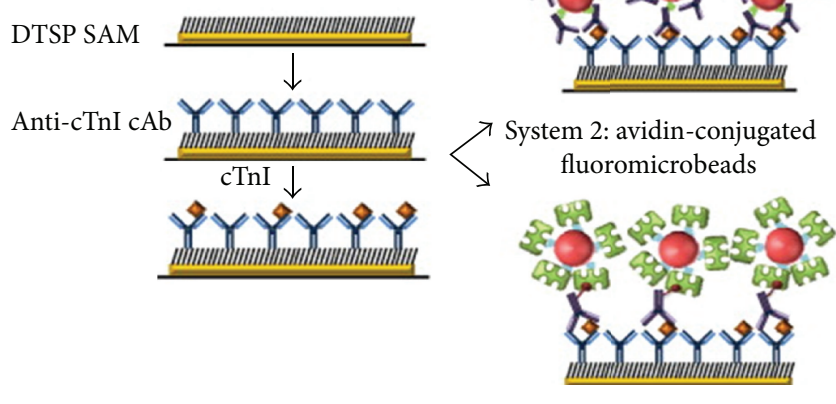

FIGURE 12: Application of the polystyrene-coated fluoromicrobeads for the detection of $\mathrm{cTnI}$ on the protein microarray (adapted from [37]).

coupling reaction. The use of fluoromicrobeads allowed detecting the cTnI in plasma samples with a range of 0.1$100 \mathrm{ng} / \mathrm{mL}$.

2.7.2. Affinity-Based Modification. The affinity interactions are used for the attachment of oligonucleotides with the fluoromicrobeads or polystyrene-coated magnetic beads. To generate the oligonucleotide conjugated fluoromicrobeads or magnetic beads, respective polystyrene-coated beads are first conjugated with the streptavidin using the EDC/NHS coupling reaction as reported by Zhang et al. [141]. As depicted
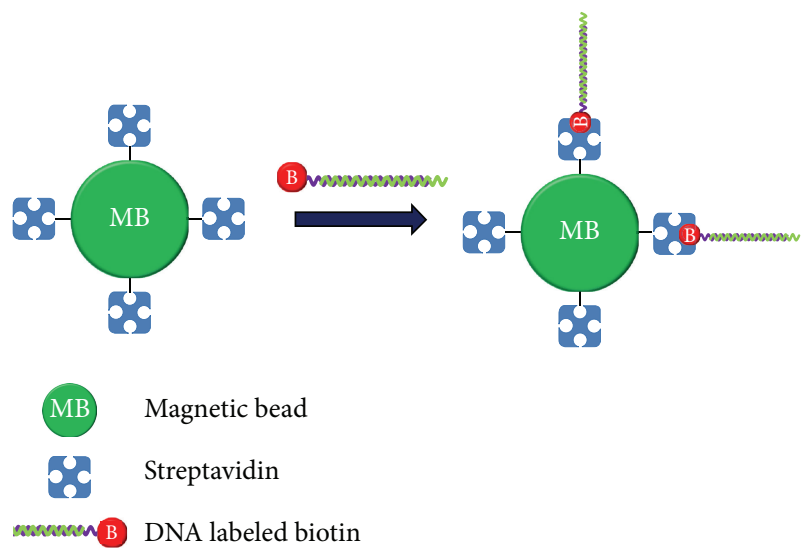

FIGURE 13: DNA attachment to the magnetic beads.

in Figure 13, the streptavidin modified beads are then allowed to incubate with the biotinylated oligonucleotides. Due to the affinity of biotin for streptavidin, the biotinylated oligonucleotides can be readily immobilized on the streptavidin coated beads.

The binding affinity of streptavidin and biotin in solution is up to $2.5 \times 10^{13}(\mathrm{~mol} / \mathrm{L})^{-1}$ [142]. This interaction is about a million times stronger than the antigen and antibody interaction. The antibodies directly immobilized onto the surface lose $90 \%$ of their biological activity [143]. However, the biotinylated antibodies immobilized on the streptavidin coated surface can retain their bioactivity [144]. 


\section{Conclusions}

Surface modification techniques of the materials used as platforms in the fabrication of biosensors are reviewed in this paper. There are several reports on materials and various methods for altering their physicochemical properties. Hence, one of these methods can be chosen according to the targeted use and needed physiochemical properties. It is important to note that the performance of the biosensor is highly dependent on the substrate material used and its meticulous modification for particular applications. Therefore, it is critical to understand the principles of a biosensor to identify the correct substrate material and its surface modification chemistry. Furthermore, it is important to look at the latest advances in the materials and techniques used for the fabrication of a biosensor before the processing.

\section{Competing Interests}

All authors declare that there is no conflict of interests.

\section{Acknowledgments}

This research was supported by the Hallym University Research Fund (HRF-201601-010). This work was also supported by the fund obtained through Industry-Academic collaboration between Biometrix Technology Inc. (Chuncheon, South Korea) and Hallym University.

\section{References}

[1] A. Sassolas, B. D. Leca-Bouvier, and L. J. Blum, "DNA biosensors and microarrays," Chemical Reviews, vol. 108, no. 1, pp. 109139, 2008.

[2] A. Cavalcanti, B. Shirinzadeh, M. Zhang, and L. C. Kretly, "Nanorobot hardware architecture for medical defense," Sensors, vol. 8, no. 5, pp. 2932-2958, 2008.

[3] R.-Q. Zhang, S.-L. Liu, W. Zhao et al., "A simple point-ofcare microfluidic immunomagnetic fluorescence assay for pathogens," Analytical Chemistry, vol. 85, no. 5, pp. 2645-2651, 2013.

[4] S. B. Nimse, K. S. Song, M. D. Sonawane, D. R. Sayyed, and T. S. Kim, "Immobilization techniques for microarray: challenges and applications," Sensors, vol. 14, no. 12, pp. 22208-22229, 2014.

[5] A. P. F. Turner, "Biosensors: sense and sensibility," Chemical Society Reviews, vol. 42, no. 8, pp. 3184-3196, 2013.

[6] L. Wu and X. Qu, "Cancer biomarker detection: recent achievements and challenges," Chemical Society Reviews, vol. 44, no. 10, pp. 2963-2997, 2015.

[7] K. Ariga, Q. Ji, T. Mori et al., "Enzyme nanoarchitectonics: organization and device application," Chemical Society Reviews, vol. 42, no. 15, pp. 6322-6345, 2013.

[8] W.-W. Zhao, J.-J. Xu, and H.-Y. Chen, "Photoelectrochemical DNA biosensors," Chemical Reviews, vol. 114, no. 15, pp. 74217441, 2014.

[9] Q. Liu, C. Wu, H. Cai, N. Hu, J. Zhou, and P. Wang, "Cell-based biosensors and their application in biomedicine," Chemical Reviews, vol. 114, no. 12, pp. 6423-6461, 2014.

[10] X. Zhao, S. Nampalli, A. J. Serino, and S. Kumar, "Immobilization of oligodeoxyribonucleotides with multiple anchors to microchips," Nucleic Acids Research, vol. 29, no. 4, pp. 955-959, 2001.

[11] P. Kumar, S. K. Agrawal, A. Misra, and K. C. Gupta, "A new heterobifunctional reagent for immobilization of biomolecules on glass surface," Bioorganic a Medicinal Chemistry Letters, vol. 14, no. 5, pp. 1097-1099, 2004.

[12] F. Secundo, "Conformational changes of enzymes upon immobilisation," Chemical Society Reviews, vol. 42, no. 15, pp. 62506261, 2013.

[13] S. Lee, S. Kim, J. Malm, O. C. Jeong, H. Lilja, and T. Laurell, "Improved porous silicon microarray based prostate specific antigen immunoassay by optimized surface density of the capture antibody," Analytica Chimica Acta, vol. 796, pp. 108-114, 2013.

[14] K. Järås, A. A. Tajudin, A. Ressine et al., "ENSAM: europium nanoparticles for signal enhancement of antibody microarrays on nanoporous silicon," Journal of Proteome Research, vol. 7, no. 3, pp. 1308-1314, 2008.

[15] C. Steinhauer, A. Ressine, G. Marko-Varga, T. Laurell, C. A. K. Borrebaeck, and C. Wingren, "Biocompatibility of surfaces for antibody microarrays: design of macroporous silicon substrates," Analytical Biochemistry, vol. 341, no. 2, pp. 204-213, 2005.

[16] K. Järås, B. Adler, A. Tojo et al., "Porous silicon antibody microarrays for quantitative analysis: measurement of free and total PSA in clinical plasma samples," Clinica Chimica Acta, vol. 414, pp. 76-84, 2012.

[17] S. W. Lee, K. Hosokawa, S. Kim et al., "A highly sensitive porous silicon (P-Si)-based human Kallikrein 2 (hK2) immunoassay platform toward accurate diagnosis of prostate cancer," Sensors, vol. 15, no. 5, pp. 11972-11987, 2015.

[18] C. Roychaudhuri, "A review on porous silicon based electrochemical biosensors: beyond surface area enhancement factor," Sensors and Actuators B: Chemical, vol. 210, pp. 310-323, 2015.

[19] A. Ressine, S. Ekström, G. Marko-Varga, and T. Laurell, "Macro-/ nanoporous silicon as a support for high-performance protein microarrays," Analytical Chemistry, vol. 75, no. 24, pp. 69686974, 2003

[20] S. Lee, E. Silajdžić, H. Yang et al., "A porous silicon immunoassay platform for fluorometric determination of $\alpha$-synuclein in human cerebrospinal fluid," Microchimica Acta, vol. 181, no. 910, pp. 1143-1149, 2014.

[21] S. Belhousse, N. Belhaneche-Bensemra, K. Lasmi et al., "Modified porous silicon for electrochemical sensor of paranitrophenol," Materials Science and Engineering B, vol. 189, pp. 76-81, 2014.

[22] N. Reta, A. Michelmore, C. Saint, B. Prieto-Simón, and N. H. Voelcker, "Porous silicon membrane-modified electrodes for label-free voltammetric detection of MS2 bacteriophage," Biosensors and Bioelectronics, vol. 80, pp. 47-53, 2016.

[23] B. Guan, A. Magenau, S. Ciampi, K. Gaus, P. J. Reece, and J. J. Gooding, "Antibody modified porous silicon microparticles for the selective capture of cells," Bioconjugate Chemistry, vol. 25, no. 7, pp. 1282-1289, 2014.

[24] S. Vutti, N. Buch-Månson, S. Schoffelen, N. Bovet, K. L. Martinez, and M. Meldal, "Covalent and stable CuAAC modification of silicon surfaces for control of cell adhesion," ChemBioChem, vol. 16, no. 5, pp. 782-791, 2015.

[25] A. M. Rossi, L. Wang, V. Reipa, and T. E. Murphy, "Porous silicon biosensor for detection of viruses," Biosensors and Bioelectronics, vol. 23, no. 5, pp. 741-745, 2007. 
[26] T. L. Lasseter, B. H. Clare, N. L. Abbott, and R. J. Hamers, "Covalently modified silicon and diamond surfaces: resistance to nonspecific protein adsorption and optimization for biosensing," Journal of the American Chemical Society, vol. 126, no. 33, pp. 10220-10221, 2004.

[27] M. Li, K.-G. Neoh, E.-T. Kang, T. Lau, and E. E. Chiong, "Surface modification of silicone with covalently immobilized and crosslinked agarose for potential application in the inhibition of infection and omental wrapping," Advanced Functional Materials, vol. 24, no. 11, pp. 1631-1643, 2014.

[28] G. MacBeath and S. L. Schreiber, "Printing proteins as microarrays for high-throughput function determination," Science, vol. 289, no. 5485, pp. 1760-1763, 2000.

[29] S. B. Nimse, M. D. Sonawane, K. S. Song, and T. Kim, "Biomarker detection technologies and future directions," The Analyst, vol. 141, no. 3, pp. 740-755, 2016.

[30] M. D. Sonawane, S. B. Nimse, K. Song, and T. Kim, "Detection, quantification, and profiling of PSA: current microarray technologies and future directions," RSC Advances, vol. 6, no. 9, pp. 7599-7609, 2016.

[31] S. B. Nimse and T. Kim, "Biological applications of functionalized calixarenes," Chemical Society Reviews, vol. 42, no. 1, pp. 366-386, 2013.

[32] K.-S. Song, S. B. Nimse, J. Kim et al., "9G DNAChip: microarray based on the multiple interactions of 9 consecutive guanines," Chemical Communications, vol. 47, no. 25, pp. 7101-7103, 2011.

[33] R. J. Chen, S. Bangsaruntip, K. A. Drouvalakis et al., "Noncovalent functionalization of carbon nanotubes for highly specific electronic biosensors," Proceedings of the National Academy of Sciences of the United States of America, vol. 100, no. 9, pp. 49844989, 2003.

[34] Y. Lu, W. Shi, J. Qin, and B. Lin, "Fabrication and characterization of paper-based microfluidics prepared in nitrocellulose membrane by wax printing," Analytical Chemistry, vol. 82, no. 1, pp. 329-335, 2010.

[35] P. Zhang, R. Zhang, M. Gao, and X. Zhang, "Novel nitrocellulose membrane substrate for efficient analysis of circulating tumor cells coupled with surface-enhanced raman scattering imaging," ACS Applied Materials and Interfaces, vol. 6, no. 1, pp. 370-376, 2014.

[36] J.-S. Lee, A. K. R. Lytton-Jean, S. J. Hurst, and C. A. Mirkin, "Silver nanoparticle-oligonucleotide conjugates based on DNA with triple cyclic disulfide moieties," Nano Letters, vol. 7, no. 7, pp. 2112-2115, 2007.

[37] S. Y. Song, Y. D. Han, K. Kim, S. S. Yang, and H. C. Yoon, "A fluoro-microbead guiding chip for simple and quantifiable immunoassay of cardiac troponin I (cTnI)," Biosensors and Bioelectronics, vol. 26, no. 9, pp. 3818-3824, 2011.

[38] S. V. Lemeshko, T. Powdrill, Y. Y. Belosludtsev, and M. Hogan, "Oligonucleotides form a duplex with non-helical properties on a positively charged surface," Nucleic Acids Research, vol. 29, no. 14, pp. 3051-3058, 2001.

[39] Z.-L. Zhi, A. K. Powell, and J. E. Turnbull, "Fabrication of carbohydrate microarrays on gold surfaces: direct attachment of nonderivatized oligosaccharides to hydrazide-modified selfassembled monolayers," Analytical Chemistry, vol. 78, no. 14, pp. 4786-4793, 2006.

[40] S. L. Pan and L. Rothberg, "Chemical control of electrode functionalization for detection of DNA hybridization by electrochemical impedance spectroscopy," Langmuir, vol. 21, no. 3, pp. 1022-1027, 2005.
[41] Z. Lu, C. M. Li, Q. Zhou, Q.-L. Bao, and X. Cui, "Covalently linked DNA/protein multilayered film for controlled DNA release," Journal of Colloid and Interface Science, vol. 314, no. 1, pp. 80-88, 2007.

[42] L.-S. Jang and H.-J. Liu, "Fabrication of protein chips based on 3-aminopropyltriethoxysilane as a monolayer," Biomedical Microdevices, vol. 11, no. 2, pp. 331-338, 2009.

[43] F. Fixe, M. Dufva, P. Telleman, and C. B. Christensen, "Functionalization of poly(methyl methacrylate) (PMMA) as a substrate for DNA microarrays," Nucleic Acids Research, vol. 32, no. 1, article e9, 2004.

[44] A. Lueking, M. Horn, H. Eickhoff, K. Büssow, H. Lehrach, and G. Walter, "Protein microarrays for gene expression and antibody screening," Analytical Biochemistry, vol. 270, no. 1, pp. 103-111, 1999.

[45] N. Zammatteo, L. Jeanmart, S. Hamels et al., "Comparison between different strategies of covalent attachment of DNA to glass surfaces to build DNA microarrays," Analytical Biochemistry, vol. 280, no. 1, pp. 143-150, 2000.

[46] M. Ozmen, K. Can, I. Akin et al., "Surface modification of glass beads with glutaraldehyde: characterization and their adsorption property for metal ions," Journal of Hazardous Materials, vol. 171, no. 1-3, pp. 594-600, 2009.

[47] C. Funk, P. M. Dietrich, T. Gross, H. Min, W. E. S. Unger, and W. Weigel, "Epoxy-functionalized surfaces for microarray applications: surface chemical analysis and fluorescence labeling of surface species," Surface and Interface Analysis, vol. 44, no. 8, pp. 890-894, 2012.

[48] S. Mahajan, P. Kumar, and K. C. Gupta, "Oligonucleotide microarrays: immobilization of phosphorylated oligonucleotides on epoxylated surface," Bioconjugate Chemistry, vol. 17, no. 5, pp. 1184-1189, 2006.

[49] M. C. Pirrung, J. D. Davis, and A. L. Odenbaugh, "Novel reagents and procedures for immobilization of DNA on glass microchips for primer extension," Langmuir, vol. 16, no. 5, pp. 2185-2191, 2000.

[50] E. Southern, K. Mir, and M. Shchepinov, "Molecular interactions on microarrays," Nature Genetics, vol. 21, no. 1, pp. 5-9, 1999.

[51] M. S. Shchepinov, S. C. Case-Green, and E. M. Southern, "Steric factors influencing hybridisation of nucleic acids to oligonucleotide arrays," Nucleic Acids Research, vol. 25, no. 6, pp. 1155-1161, 1997.

[52] D. A. Tomalia, A. M. Naylor, and W. A. Goddard III, "Starbust dendrimers: molecular-level control of size, shape, surface chemistry, topology, and flexibility from atoms to macroscopic matter," Angewandte Chemie-International Edition in English, vol. 29, no. 2, pp. 138-175, 1990.

[53] R. Benters, C. M. Niemeyer, D. Drutschmann, D. Blohm, and D. Wöhrle, "DNA microarrays with PAMAM dendritic linker systems," Nucleic Acids Research, vol. 30, no. 2, p. e10, 2002.

[54] J. H. Moon, J. W. Shin, S. Y. Kim, and J. W. Park, "Formation of uniform aminosilane thin layers: an imine formation to measure relative surface density of the amine group," Langmuir, vol. 12, no. 20, pp. 4621-4624, 1996.

[55] J. C. Alwine, D. J. Kemp, and G. R. Stark, "Method for detection of specific RNAs in agarose gels by transfer to diazobenzyloxymethyl-paper and hybridization with DNA probes," Proceedings of the National Academy of Sciences of the United States of America, vol. 74, no. 12, pp. 5350-5354, 1977.

[56] P. L. Dolan, Y. Wu, L. K. Ista, R. L. Metzenberg, M. A. Nelson, and G. P. Lopez, "Robust and efficient synthetic method for 
forming DNA microarrays," Nucleic Acids Research, vol. 29, no. 21, article e107, 2001.

[57] S. B. Nimse, J. Kim, K.-S. Song et al., "Selective recognition of the ditopic trimethylammonium cations by water-soluble aminocalix[4]arene," Tetrahedron Letters, vol. 52, no. 29, pp. 3751-3755, 2011.

[58] V.-T. Ta, S. B. Nimse, K.-S. Song et al., "Characterization of the mixed self-assembled monolayer at the molecular scale," Chemical Communications, vol. 47, no. 40, pp. 11261-11263, 2011.

[59] S. Li, Y. Y. Chen, and X. R. Lu, "Syntheses of novel tripodal calix $[n]$ cryptands $(n=4,6)$ and their extraction abilities toward cations," European Journal of Organic Chemistry, vol. 2000, no. 3, pp. 485-490, 2000.

[60] Y. Lee, E. K. Lee, Y. W. Cho et al., "ProteoChip: a highly sensitive protein microarray prepared by a novel method of protein immobilization for application of protein-protein interaction studies," Proteomics, vol. 3, no. 12, pp. 2289-2304, 2003.

[61] S. W. Oh, J. D. Moon, H. J. Lim et al., "Calixarene derivative as a tool for highly sensitive detection and oriented immobilization of proteins in a microarray format through noncovalent molecular interaction," The FASEB Journal, vol. 19, no. 10, pp. 1335-1337, 2005.

[62] S. B. Nimse, K.-S. Song, J. Kim, D. R. Sayyed, and T. Kim, "9G DNAChip technology: self-assembled monolayer (SAM) of ssDNA for ultra-sensitive detection of biomarkers," International Journal of Molecular Sciences, vol. 14, no. 3, pp. 5723-5733, 2013.

[63] V.-T. Nguyen, S. B. Nimse, K.-S. Song et al., "HPAI 9G DNAChip: discrimination of highly pathogenic influenza virus genes," Chemical Communications, vol. 48, no. 38, pp. 45824584, 2012.

[64] K.-S. Song, S. B. Nimse, J. Kim, D. R. Sayyed, and T. Kim, "A new platform for a convenient genotyping system," Chemical Communications, vol. 49, no. 26, pp. 2661-2663, 2013.

[65] Y. Cui, Q. Wei, H. Park, and C. M. Lieber, "Nanowire nanosensors for highly sensitive and selective detection of biological and chemical species," Science, vol. 293, no. 5533, pp. 1289-1292, 2001.

[66] R. J. Chen, Y. Zhang, D. Wang, and H. Dai, "Noncovalent sidewall functionalization of single-walled carbon nanotubes for protein immobilization," Journal of the American Chemical Society, vol. 123, no. 16, pp. 3838-3839, 2001.

[67] F. Hennrich, C. Chan, V. Moore, M. Rolandi, and M. O'Connell, Carbon Nanotubes Properties and Applications, Taylor \& Francis Group, Abingdon, UK, 2006.

[68] S. Iijima, "Helical microtubules of graphitic carbon," Nature, vol. 354, no. 6348, pp. 56-58, 1991.

[69] C. Singh, M. Shaffer, I. Kinloch, and A. Windle, "Production of aligned carbon nanotubes by the CVD injection method," Physica B: Condensed Matter, vol. 323, no. 1-4, pp. 339-340, 2002.

[70] H. Kuzmany, A. Kukovecz, F. Simon, M. Holzweber, C. Kramberger, and T. Pichler, "Functionalization of carbon nanotubes," Synthetic Metals, vol. 141, no. 1-2, pp. 113-122, 2004.

[71] C. Journet, W. K. Maser, P. Bernier et al., "Large-scale production of single-walled carbon nanotubes by the electric-arc technique," Nature, vol. 388, no. 6644, pp. 756-758, 1997.

[72] A. Thess, R. Lee, P. Nikolaev et al., "Crystalline ropes of metallic carbon nanotubes,” Science, vol. 273, no. 5274, pp. 483-487, 1996.

[73] M. Foldvari and M. Bagonluri, "Carbon nanotubes as functional excipients for nanomedicines: II. Drug delivery and biocompatibility issues," Nanomedicine, vol. 4, no. 3, pp. 183-200, 2008.
[74] Z. Liu, J. T. Robinson, S. M. Tabakman, K. Yang, and H. Dai, "Carbon materials for drug delivery \& cancer therapy," Materials Today, vol. 14, no. 7-8, pp. 316-323, 2011.

[75] W. Wei, A. Sethuraman, C. Jin, N. A. Monteiro-Riviere, and R. J. Narayan, "Biological properties of carbon nanotubes," Journal of Nanoscience and Nanotechnology, vol. 7, no. 4-5, pp. 1284-1297, 2007.

[76] D. Cui, "Advances and prospects on biomolecules functionalized carbon nanotubes," Journal of Nanoscience and Nanotechnology, vol. 7, no. 4-5, pp. 1298-1314, 2007.

[77] N. Saifuddin, A. Z. Raziah, and A. R. Junizah, "Carbon nanotubes: a review on structure and their interaction with proteins," Journal of Chemistry, vol. 2013, Article ID 676815, 18 pages, 2013.

[78] S. Banerjee, T. Hemraj-Benny, and S. S. Wong, "Covalent surface chemistry of single-walled carbon nanotubes," Advanced Materials, vol. 17, no. 1, pp. 17-29, 2005.

[79] F. Bomboi, A. Bonincontro, C. La Mesa, and F. Tardani, "Interactions between single-walled carbon nanotubes and lysozyme," Journal of Colloid and Interface Science, vol. 355, no. 2, pp. 342347, 2011.

[80] K. Matsuura, T. Saito, T. Okazaki, S. Ohshima, M. Yumura, and S. Iijima, "Selectivity of water-soluble proteins in singlewalled carbon nanotube dispersions," Chemical Physics Letters, vol. 429, no. 4-6, pp. 497-502, 2006.

[81] D. Nepal and K. E. Geckeler, "pH-sensitive dispersion and debundling of single-walled carbon nanotubes: lysozyme as a tool," Small, vol. 2, no. 3, pp. 406-412, 2006.

[82] P. Asuri, S. S. Karajanagi, H. Yang, T.-J. Yim, R. S. Kane, and J. S. Dordick, "Increasing protein stability through control of the nanoscale environment," Langmuir, vol. 22, no. 13, pp. 58335836, 2006.

[83] P. Asuri, S. S. Karajanagi, E. Sellitto, D.-Y. Kim, R. S. Kane, and J. S. Dordick, "Water-soluble carbon nanotube-enzyme conjugates as functional biocatalytic formulations," Biotechnology and Bioengineering, vol. 95, no. 5, pp. 804-811, 2006.

[84] E. Ostuni, R. G. Chapman, R. E. Holmlin, S. Takayama, and G. M. Whitesides, "A survey of structure-property relationships of surfaces that resist the adsorption of protein," Langmuir, vol. 17, no. 18 , pp. 5605-5620, 2001.

[85] R. E. Holmlin, X. Chen, R. G. Chapman, S. Takayama, and G. M. Whitesides, "Zwitterionic SAMs that resist nonspecific adsorption of protein from aqueous buffer," Langmuir, vol. 17, no. 9, pp. 2841-2850, 2001.

[86] N. Nakayama-Ratchford, S. Bangsaruntip, X. M. Sun, K. Welsher, and H. Dai, "Noncovalent functionalization of carbon nanotubes by fluorescein-polyethylene glycol: supramolecular conjugates with $\mathrm{pH}$-dependent absorbance and fluorescence," Journal of the American Chemical Society, vol. 129, no. 9, pp. 2448-2449, 2007.

[87] A. Satake, Y. Miyajima, and Y. Kobuke, "Porphyrin-carbon nanotube composites formed by noncovalent polymer wrapping," Chemistry of Materials, vol. 17, no. 4, pp. 716-724, 2005.

[88] J. Zhang, J. K. Lee, Y. Wu, and R. W. Murray, "Photoluminescence and electronic interaction of anthracene derivatives adsorbed on sidewalls of single-walled carbon nanotubes," Nano Letters, vol. 3, no. 3, pp. 403-407, 2003.

[89] W. Z. Yuan, J. Z. Sun, Y. Dong et al., "Wrapping carbon nanotubes in pyrene-containing poly(phenylacetylene) chains: solubility, stability, light emission, and surface photovoltaic properties," Macromolecules, vol. 39, no. 23, pp. 8011-8020, 2006. 
[90] V. V. Didenko, V. C. Moore, D. S. Baskin, and R. E. Smalley, "Visualization of individual single-walled carbon nanotubes by fluorescent polymer wrapping," Nano Letters, vol. 5, no. 8, pp. 1563-1567, 2005.

[91] D. Tasis, N. Tagmatarchis, A. Bianco, and M. Prato, "Chemistry of carbon nanotubes," Chemical Reviews, vol. 106, no. 3, pp. 1105-1136, 2006.

[92] V. Georgakilas, K. Kordatos, M. Prato, D. M. Guldi, M. Holzinger, and A. Hirsch, "Organic functionalization of carbon nanotubes," Journal of the American Chemical Society, vol. 124, no. 5, pp. 760-761, 2002.

[93] M. W. Marshall, S. Popa-Nita, and J. G. Shapter, "Measurement of functionalised carbon nanotube carboxylic acid groups using a simple chemical process," Carbon, vol. 44, no. 7, pp. 1137-1141, 2006.

[94] P. D. Tam, N. Van Hieu, N. D. Chien, A.-T. Le, and M. Anh Tuan, "DNA sensor development based on multi-wall carbon nanotubes for label-free influenza virus (type A) detection," Journal of Immunological Methods, vol. 350, no. 1-2, pp. 118-124, 2009.

[95] K. Awasthi, D. P. Singh, S. K. Singh, D. Dash, and O. N. Srivastava, "Attachment of biomolecules (protein and DNA) to amino-functionalized carbon nanotubes," New Carbon Materials, vol. 24, no. 4, pp. 301-306, 2009.

[96] H. Li, R. B. Martin, B. A. Harruff, R. A. Carino, L. F. Allard, and Y.-P. Sun, "Single-walled carbon nanotubes tethered with porphyrins: synthesis and photophysical properties," Advanced Materials, vol. 16, no. 11, pp. 896-900, 2004.

[97] Z. Guo, F. Du, D. M. Ren et al., "Covalently porphyrinfunctionalized single-walled carbon nanotubes: a novel photoactive and optical limiting donor-acceptor nanohybrid," Journal of Materials Chemistry, vol. 16, no. 29, pp. 3021-3030, 2006.

[98] Z. Li, Y. Q. Dong, M. Haussler et al., "Synthesis of light emission from, and optical power limiting in soluble single-walled carbon nanotubes functionalized by disubstituted polyacetylenes," The Journal of Physical Chemistry B, vol. 110, no. 5, pp. 23022309, 2006.

[99] A. Eitan, K. Jiang, D. Dukes, R. Andrews, and L. S. Schadler, "Surface modification of multiwalled carbon nanotubes: toward the tailoring of the interface in polymer composites," Chemistry of Materials, vol. 15, no. 16, pp. 3198-3201, 2003.

[100] A. W. Martinez, S. T. Phillips, G. M. Whitesides, and E. Carrilho, "Diagnostics for the developing world: microfluidic paperbased analytical devices," Analytical Chemistry, vol. 82, no. 1, pp. 3-10, 2010.

[101] P. J. Bracher, M. Gupta, and G. M. Whitesides, "Patterning precipitates of reactions in paper," Journal of Materials Chemistry, vol. 20, no. 24, pp. 5117-5122, 2010.

[102] W. A. Zhao and A. van den Berg, "Lab on paper," Lab on a Chip, vol. 8, no. 12, pp. 1988-1991, 2008.

[103] W. Dungchai, O. Chailapakul, and C. S. Henry, "A low-cost, simple, and rapid fabrication method for paper-based microfluidics using wax screen-printing," Analyst, vol. 136, no. 1, pp. 77-82, 2011.

[104] S. M. Z. Hossain, R. E. Luckham, A. M. Smith et al., "Development of a bioactive paper sensor for detection of neurotoxins using piezoelectric inkjet printing of sol-gel-derived bioinks," Analytical Chemistry, vol. 81, no. 13, pp. 5474-5483, 2009.

[105] J. Yu, L. Ge, J. Huang, S. Wang, and S. Ge, "Microfluidic paper-based chemiluminescence biosensor for simultaneous determination of glucose and uric acid," Lab on a Chip, vol. 11, no. 7, pp. 1286-1291, 2011.
[106] J. P. Comer, "Semiquantitative specific test paper for glucose in urine," Analytical Chemistry, vol. 28, no. 11, pp. 1748-1750, 1956.

[107] P. Von Lode, "Point-of-care immunotesting: approaching the analytical performance of central laboratory methods," Clinical Biochemistry, vol. 38, no. 7, pp. 591-606, 2005.

[108] D. D. Liana, B. Raguse, J. J. Gooding, and E. Chow, "Recent advances in paper-based sensors," Sensors, vol. 12, no. 9, pp. 11505-11526, 2012.

[109] A. K. Ellerbee, S. T. Phillips, A. C. Siegel et al., "Quantifying colorimetric assays in paper-based microfluidic devices by measuring the transmission of light through paper," Analytical Chemistry, vol. 81, no. 20, pp. 8447-8452, 2009.

[110] A. W. Martinez, S. T. Phillips, Z. Nie et al., "Programmable diagnostic devices made from paper and tape," Lab on a Chip, vol. 10, no. 19, pp. 2499-2504, 2010.

[111] P. J. Bracher, M. Gupta, and G. M. Whitesides, "Patterned paper as a template for the delivery of reactants in the fabrication of planar materials," Soft Matter, vol. 6, no. 18, pp. 4303-4309, 2010.

[112] R. E. Luckham and J. D. Brennan, "Bioactive paper dipstick sensors for acetylcholinesterase inhibitors based on solgel/enzyme/gold nanoparticle composites," Analyst, vol. 135, no. 8, pp. 2028-2035, 2010.

[113] M. Cretich, V. Sedini, F. Damin, M. Pelliccia, L. Sola, and M. Chiari, "Coating of nitrocellulose for colorimetric DNA microarrays," Analytical Biochemistry, vol. 397, no. 1, pp. 84-88, 2010.

[114] E. M. Fenton, M. R. Mascarenas, G. P. López, and S. S. Sibbett, "Multiplex lateral-flow test strips fabricated by two-dimensional shaping," ACS Applied Materials and Interfaces, vol. 1, no. 1, pp. 124-129, 2009.

[115] A. W. Martinez, S. T. Phillips, E. Carrilho, S. W. Thomas III, H. Sindi, and G. M. Whitesides, "Simple telemedicine for developing regions: camera phones and paper-based microfluidic devices for real-time, off-site diagnosis," Analytical Chemistry, vol. 80, no. 10, pp. 3699-3707, 2008.

[116] H. Li, S. Bergeron, and D. Juncker, "Microarray-to-microarray transfer of reagents by snapping of two chips for crossreactivity-free multiplex immunoassays," Analytical Chemistry, vol. 84, no. 11, pp. 4776-4783, 2012.

[117] A. P. Alivisatos, W. Gu, and C. Larabell, "Quantum dots as cellular probes," Annual Review of Biomedical Engineering, vol. 7, pp. 55-76, 2005.

[118] M. Law, L. E. Greene, J. C. Johnson, R. Saykally, and P. Yang, "Nanowire dye-sensitized solar cells," Nature Materials, vol. 4, no. 6, pp. 455-459, 2005.

[119] S. B. Fuller, E. J. Wilhelm, and J. M. Jacobson, "Ink-jet printed nanoparticle microelectromechanical systems," Journal of Microelectromechanical Systems, vol. 11, no. 1, pp. 54-60, 2002.

[120] D. J. O'Shannessy, M. Brigham-Burke, and K. Peck, "Immobilization chemistries suitable for use in the BIAcore surface plasmon resonance detector," Analytical Biochemistry, vol. 205, no. 1, pp. 132-136, 1992.

[121] R. W. Nelson and J. R. Krone, "Advances in surface plasmon resonance biomolecular interaction analysis mass spectrometry (BIA/MS)," Journal of Molecular Recognition, vol. 12, no. 2, pp. 77-93, 1999.

[122] P. Gomes, E. Giralt, and D. Andreu, "Direct single-step surface plasmon resonance analysis of interactions between small peptides and immobilized monoclonal antibodies," Journal of Immunological Methods, vol. 235, no. 1-2, pp. 101-111, 2000. 
[123] R. White, C. Winston, M. Gonen et al., "Current utility of staging laparoscopy for pancreatic and peripancreatic neoplasms," Journal of the American College of Surgeons, vol. 206, no. 3, pp. 445-450, 2008.

[124] J. Kulig, T. Popiela, A. Zajac, S. Klek, and P. Kołodziejczyk, “The value of imaging techniques in the staging of pancreatic cancer," Surgical Endoscopy and Other Interventional Techniques, vol. 19, no. 3, pp. 361-365, 2005.

[125] N. C. Tansil and Z. Gao, "Nanoparticles in biomolecular detection," Nano Today, vol. 1, no. 1, pp. 28-37, 2006.

[126] A. J. Di Pasqua, R. E. Mishler, Y.-L. Ship, J. C. Dabrowiak, and T. Asefa, "Preparation of antibody-conjugated gold nanoparticles," Materials Letters, vol. 63, no. 21, pp. 1876-1879, 2009.

[127] H. Otsuka, Y. Akiyama, Y. Nagasaki, and K. Kataoka, "Quantitative and reversible lectin-induced association of gold nanoparticles modified with $\alpha$-lactosyl- $\omega$-mercapto-poly(ethylene glycol)," Journal of the American Chemical Society, vol. 123, no. 34, pp. 8226-8230, 2001.

[128] H. Liao and J. H. Hafner, "Gold nanorod bioconjugates," Chemistry of Materials, vol. 17, no. 18, pp. 4636-4641, 2005.

[129] W. Eck, G. Craig, A. Sigdel et al., "PEGylated gold nanoparticles conjugated to monoclonal F19 antibodies as targeted labeling agents for human pancreatic carcinoma tissue," ACS Nano, vol. 2, no. 11, pp. 2263-2272, 2008.

[130] A. A. Vertegel, R. W. Siegel, and J. S. Dordick, "Silica nanoparticle size influences the structure and enzymatic activity of adsorbed lysozyme," Langmuir, vol. 20, no. 16, pp. 6800-6807, 2004.

[131] D. D. Lan, B. B. Li, and Z. Z. Zhang, "Chemiluminescence flow biosensor for glucose based on gold nanoparticle-enhanced activities of glucose oxidase and horseradish peroxidase," Biosensors and Bioelectronics, vol. 24, no. 4, pp. 940-944, 2008.

[132] X. C. Shen, Q. Yuan, H. Liang, H. Yan, and X. He, "Hysteresis effects of the interaction between serum albumins and silver nanoparticles," Science in China Series B: Chemistry, vol. 46, pp. 387-398, 2003.

[133] S. L. Smitha, K. M. Nissamudeen, D. Philip, and K. G. Gopchandran, "Studies on surface plasmon resonance and photoluminescence of silver nanoparticles," Spectrochimica Acta-Part A: Molecular and Biomolecular Spectroscopy, vol. 71, no. 1, pp. 186190, 2008.

[134] G. A. Petkova, C. K. Záruba, P. Žvátora, and V. Král, “Gold and silver nanoparticles for biomolecule immobilization and enzymatic catalysis," Nanoscale Research Letters, vol. 7, no. 1, pp. 287-296, 2012.

[135] J. C. Riboh, A. J. Haes, A. D. McFarland, C. R. Yonzon, and R. P. Van Duyne, "A nanoscale optical biosensor: real-time immunoassay in physiological buffer enabled by improved nanoparticle adhesion," The Journal of Physical Chemistry B, vol. 107, no. 8, pp. 1772-1780, 2003.

[136] N. Nath and A. Chilkoti, "A colorimetric gold nanoparticle sensor to interrogate biomolecular interactions in real time on a surface," Analytical Chemistry, vol. 74, no. 3, pp. 504-509, 2002.

[137] Y. Zhang, R. Huang, X. Zhu, L. Wang, and C. Wu, "Synthesis, properties, and optical applications of noble metal nanoparticle-biomolecule conjugates," Chinese Science Bulletin, vol. 57, no. 2-3, pp. 238-246, 2012.

[138] C. Loos, T. Syrovets, A. Musyanovych et al., "Functionalized polystyrene nanoparticles as a platform for studying bio-nano interactions," Beilstein Journal of Nanotechnology, vol. 5, pp. 2403-2412, 2014.
[139] E. G. Sowers, J. G. Wells, and N. A. Strockbine, "Evaluation of commercial latex reagents for identification of $\mathrm{O} 157$ and $\mathrm{H} 7$ antigens of Escherichia coli," Journal of Clinical Microbiology, vol. 34, no. 5, pp. 1286-1289, 1996.

[140] L. S. Wong, K. Okrasa, and J. MicKlefield, "Site-selective immobilisation of functional enzymes on to polystyrene nanoparticles," Organic and Biomolecular Chemistry, vol. 8, no. 4, pp. 782787,2010

[141] Z. Zhang, H. Zhu, Y. Tang et al., "Preparation and application of streptavidin magnetic particles," Science in China, Series B: Chemistry, vol. 50, no. 1, pp. 127-134, 2007.

[142] E. A. Bayer, H. Ben-Hur, and M. Wilchek, "Isolation and properties of streptavidin," Methods in Enzymology, vol. 184, pp. 80-93, 1990.

[143] L. Välimaa, K. Pettersson, J. Rosenberg, M. Karp, and T. Lövgren, "Quantification of streptavidin adsorption in microtitration wells," Analytical Biochemistry, vol. 331, no. 2, pp. 376384, 2004.

[144] J. E. Butler, "Solid supports in enzyme-linked immunosorbent assay and other solid-phase immunoassays," Methods, vol. 22, no. 1 , pp. $4-23,2000$. 

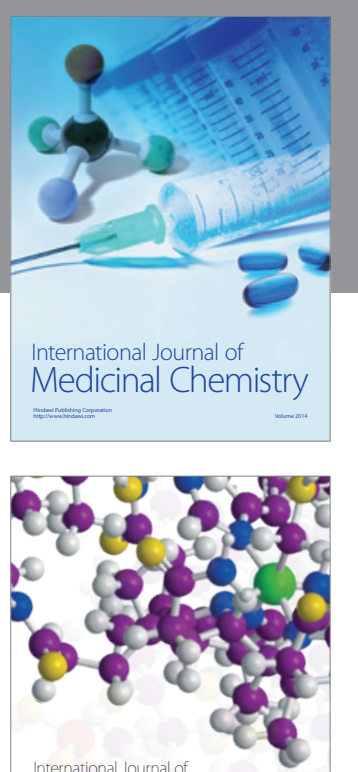

Carbohydrate Chemistry

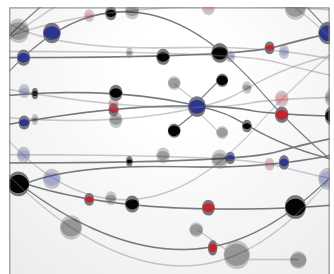

The Scientific World Journal
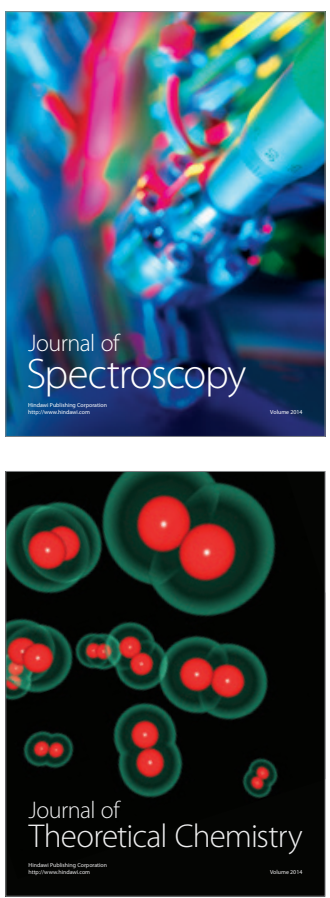
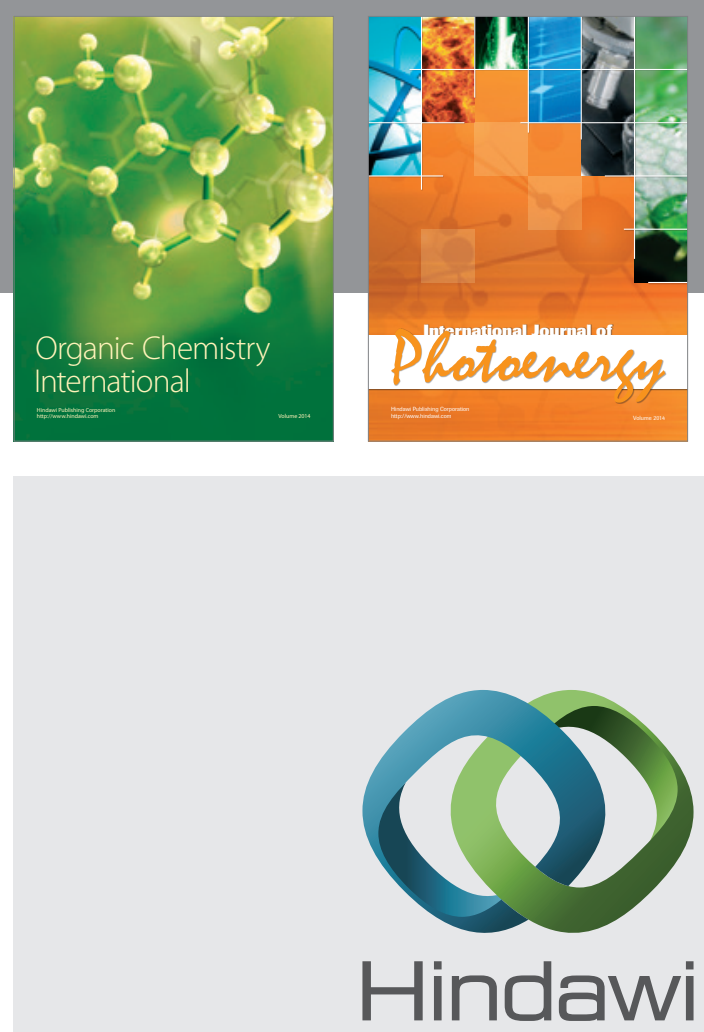

Submit your manuscripts at

http://www.hindawi.com

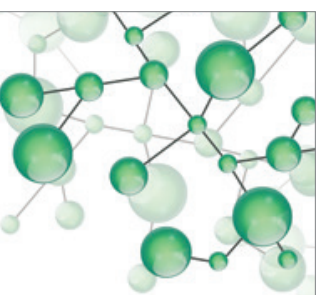

International Journal of

Inorganic Chemistry

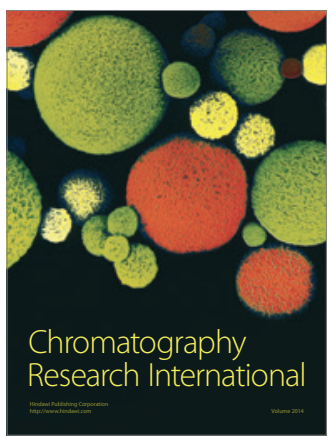

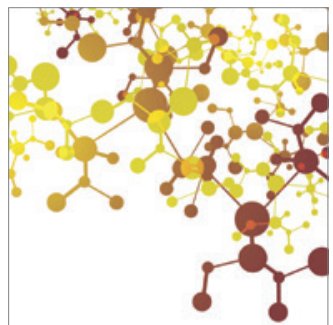

Applied Chemistry
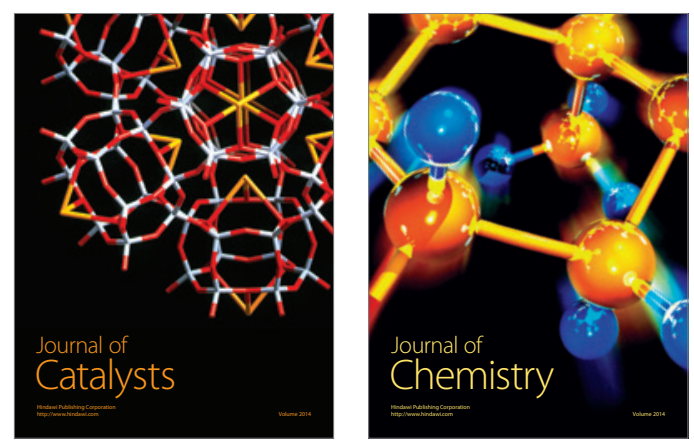
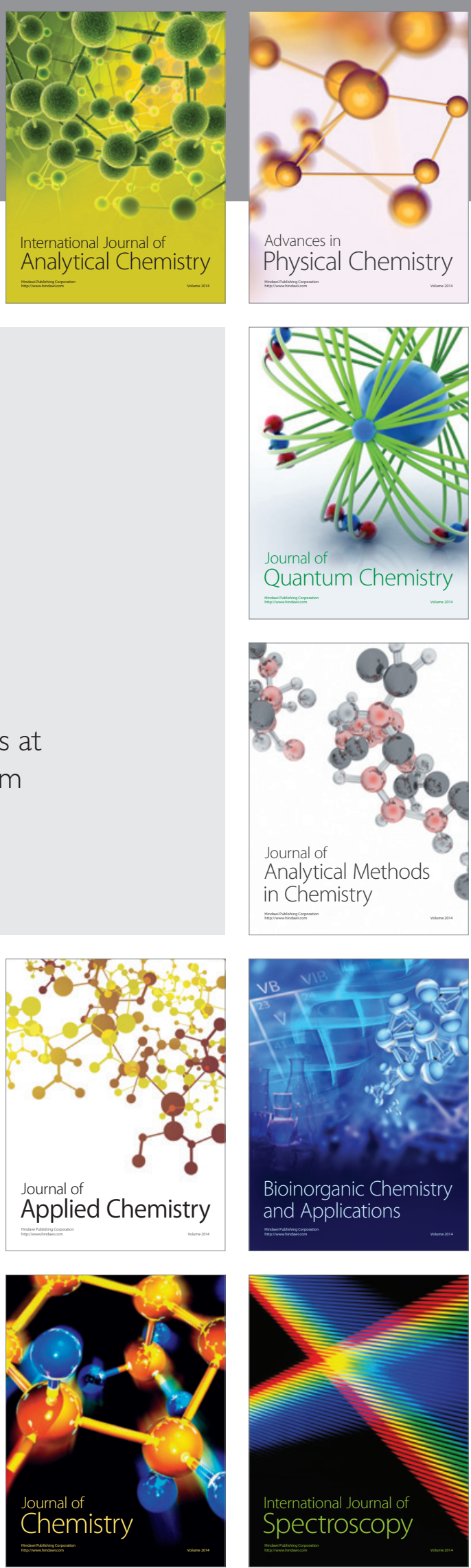